Article

\title{
Structured binder-free MWW-type titanosilicate with Si-rich shell for selective and durable propylene epoxidation
}

\author{
Jinpeng Yin, Xin Jin, Hao Xu \#, Yejun Guan, Rusi Peng, Li Chen, Jingang Jiang, Peng Wu * \\ Shanghai Key Laboratory of Green Chemistry and Chemical Processes, School of Chemistry and Molecular Engineering, East China Normal University, \\ Shanghai 200062, China
}

\section{A R T I C L E I N F O}

\section{Article history:}

Received 11 December 2020

Accepted 11 January 2021

Available online 5 May 2021

\section{Keywords:}

Propylene epoxidation

Titanosilicate

Binder-free formed catalyst

Recrystallization

Microenvironment

\begin{abstract}
A B S T R A C T
Selective and durable fixed-bed catalysts are highly desirable for developing eco-efficient HPPO (hydrogen peroxide propylene oxide) process. The powder titanosilicate catalysts must be shaped before being applied in industrial processes. As the essential additives for preparing formed catalysts, binders are usually the catalytically inert components, but they would cover the surface and pore mouth of zeolite, thereby declining the accessibility of active sites. By recrystallizing the binder (silica)/Ti-MWW extrudates with the assistance of dual organic structure-directing agents, the silica binder was converted into MWW zeolite phase to form a structured binder-free Ti-MWW zeolite with Si-rich shell, which enhanced the diffusion efficiency and maintained the mechanical strength. Meanwhile, due to the partial dissolution of Si in the Ti-MWW matrix, abundant silanol nests formed and part of framework $\mathrm{TiO}_{4}$ species were transferred into open $\mathrm{TiO}_{6}$ ones, improving the accumulation and activation ability of $\mathrm{H}_{2} \mathrm{O}_{2}$ inside the monolith. Successive piperidine treatment and fluoridation of the binder-free Ti-MWW further enhanced the $\mathrm{H}_{2} \mathrm{O}_{2}$ activation and oxygen transfer ability of the active Ti sites, and stabilized the Ti-OOH intermediate through hydrogen bond formed between the end $\mathrm{H}$ in $\mathrm{Ti}-\mathrm{OOH}$ and the adjacent $\mathrm{Si}-\mathrm{F}$ species, thus achieving a more efficient epoxidation process. Additionally, the side reaction of PO hydrolysis was inhibited because the modification effectively quenched numerous $\mathrm{Si}-\mathrm{OH}$ groups. The lifetime of the modified binder-free Ti-MWW catalyst was $2400 \mathrm{~h}$ with the $\mathrm{H}_{2} \mathrm{O}_{2}$ conversion and $\mathrm{PO}$ selectivity both above $99.5 \%$.
\end{abstract}

(C) 2021, Dalian Institute of Chemical Physics, Chinese Academy of Sciences. Published by Elsevier B.V. All rights reserved.

\section{Introduction}

Propylene oxide (PO) is one of the important propylene derivatives with high reactivity, which is used extensively as raw material for the manufacture of numerous commercial chemicals (e.g., propylene glycols, polyurethane, unsaturated resins, and surfactants) [1-3]. The global PO production capacity has exceeded 11 million metric tons in 2017 and is forecasted to continue gaining at a compounded annual growth rate of about
5.9\% during 2019-2024 [4]. Currently, the industrial routes for PO production mainly include the classic chlorohydrin process (CP), the co-oxidation process (ie., propylene oxide/t-butyl alcohol process (PO/TBA), styrene monomer propylene oxide process (SMPO), and cumene hydroperoxide propylene oxide process (CHPO)), and the titanosilicate-catalyzed hydrogen peroxide propylene oxide process (HPPO). Among these technologies, the HPPO process is considered to be the most advantageous one because it is highly economical and ecofriendly,

\footnotetext{
* Corresponding author. Tel/Fax: +86-21-62232292; E-mail: pwu@chem.ecnu.edu.cn

* Corresponding author. E-mail: hxu@chem.ecnu.edu.cn

This work was supported by the National Natural Science Foundation of China (21872052, 21533002, 21972044), the Ministry of Science and Technology of the People's Republic of China (2016YFA0202804), and the Fundamental Research Funds for the Central Universities.

DOI: 10.1016/S1872-2067(20)63759-7 | http://www.sciencedirect.com/journal/chinese-journal-of-catalysis | Chin. J. Catal., Vol. 42 , No. 9, September 2021
} 
giving water as the theoretical byproduct and achieving high PO selectivity under mild reaction conditions [5-7]. Based on the TS- $1 / \mathrm{H}_{2} \mathrm{O}_{2} /$ Methanol $(\mathrm{MeOH})$ system, the HPPO process has been commercialized in fixed-bed reactors under continuous flow conditions by Dow/BASF, Evonik/Uhde and SINOPEC. Unfortunately, the solvent $\mathrm{MeOH}$ accelerates the side reactions of PO solvolysis because of its protic nature (Scheme S1(a)), significantly lowering PO selectivity, although it also plays a key role in stabilizing the $\mathrm{Ti}-\mathrm{OOH}$ intermediate to achieve high conversion [8]. The purification and separation of PO from the reaction system then increases the operation difficulty and complexity as well as energy consumption and cost due to the azeotropic problem of $\mathrm{MeOH}$ and PO. Notably, in our previous study, it was found that for propylene epoxidation, Ti-MWW showed superior catalytic performance in the solvent of acetonitrile $(\mathrm{MeCN})$ than $\mathrm{TS}-1$ with $\mathrm{MeOH}$ as the solvent [9]. The presence of aprotic and weak basic MeCN could efficiently prohibited the side reactions of PO solvolysis, greatly improving the PO selectivity (Scheme S1(b)). Therefore, it is of great academic and industrial significance to design and prepare an industrial Ti-MWW catalyst with MeCN as the solvent.

The industrial HPPO process is generally carried out in a fixed-bed reactor, where the shaped titanosilicate catalysts with satisfying mechanical strength are necessary to decrease the pressure drop $[10,11]$. As the essential additives for preparing formed catalysts, binders are usually the catalytically inert components, such as silica, alumina and carborundum, the introduction of which would inevitably reduce the proportion of available active components in the whole catalyst [12-14]. More importantly, the massive binders would cover the surface and pore mouth of zeolite to block partial micropores to some extent, thereby declining the accessibility of active sites and utilization of active sites. Therefore, the design of high-performance industrial Ti-MWW catalyst should eliminate the negative impact of binders on the diffusion of substrates to the active sites and also maintain the high mechanical strength. Converting the binders into the corresponding pure zeolite phase without destroying its macroscopic body is considered as a promising approach to conquer the negative effect of the binders. Specifically, recrystallizing the binder/zeolite extrudates into the fully-crystalline zeolite materials by hydrothermal or dry-gel conversion (DGC) method with the assistant of corresponding organic structure directing agent (SDA) is industrially feasible. At present, this strategy has been only applied to the synthesis of monolithic MFI-type aluminosilicate (ZSM-5) and TS-1 [14,15]. Monolithic Ti-MWW zeolite cannot be obtained by the recrystallization process with hydrothermal or DGC method using cheaper SDA such as piperidine (PI) or hexamethyleneimine (HMI) $[16,17]$. Undoubtedly, it is still challenging to synthesize the binder-free formed Ti-MWW catalyst with fully-zeolitic phase.

At present, the epoxidation mechanism involved in tetrahedral framework Ti sites has been widely investigated and accepted [18-20]. Namely, $\mathrm{H}_{2} \mathrm{O}_{2}$ is first adsorbed on the isolated $\mathrm{Ti}$ site and then activated to generate the $\mathrm{Ti}-\mathrm{O}^{\alpha}-\mathrm{O}^{\beta}-\mathrm{H}$ or $\mathrm{Ti}-\left(\eta^{2}-\mathrm{O}_{2}\right)$ intermediates irreversibly [18]. The two intermediates can be interconvertible in the presence of $\mathrm{H}_{2} \mathrm{O}$, and the
Ti-OOH species are mainly responsible for the epoxidation $[21,22]$. Then, the Ti-OOH species react with propylene, transferring the active $\mathrm{O}^{\alpha}$ atom to its double bond to form $\mathrm{PO}$, or with $\mathrm{H}_{2} \mathrm{O}_{2}$ for oxidative decomposition through free radical reaction, where the $0^{\alpha}$ transfer is preferred [23-25]. Therefore, modifying the active Ti sites in Ti-MWW matrix at the atomic levels (e.g., coordination state, electronic structure and hydrophilicity/hydrophobicity) is expected to improve the activation of $\mathrm{H}_{2} \mathrm{O}_{2}$ and promote the $\mathrm{O}^{\alpha}$ transfer, so as to prepare the high-performance Ti-MWW extrudates. In terms of the coordination state of $\mathrm{Ti}$ sites, the penta-coordinated and hexa-coordinated framework $\mathrm{Ti}$ with higher coordination number exhibited the better epoxidation activity in comparison to the perfect tetrahedral framework Ti (Ti(OSi) 4 ) [17,26-28]. For example, PI-assisted structural rearrangement could effectively improve the epoxidation reactivity of Ti-MWW due to the newly formed hexa-coordinated framework Ti species [16,17]. And the tripodal defective $\mathrm{Ti}\left(\mathrm{Ti}(\mathrm{OSi})_{3} \mathrm{OH}\right)$ also showed superior activity than the perfect ones $[24,29,30]$. The introduction of various heteroatoms (e.g., $\mathrm{Zn}, \mathrm{La}$ and $\mathrm{F}$ ) to improve the electropositivity of Ti sites is also able to boost the epoxidation performance [31-34]. Suitable hydrophilicity/hydrophobicity of Ti-zeolites is also one of the key factors determining the catalytic performance. The hydrophilicity inside pores of the Ti-zeolites, especially nearby the active $\mathrm{Ti}$ sites, facilitates the epoxidation, because it promotes the enrichment of $\mathrm{H}_{2} \mathrm{O}_{2}$ and affects the excess free energies of the transition states via hydrogen-bonding solvents [35]. Meanwhile, the hydrophobic exterior of Ti-zeolites could effectively adsorb the organic alkene substrates, resulting in high reactivity [36].

For the Ti-MWW/ $/ \mathrm{H}_{2} \mathrm{O}_{2} / \mathrm{MeCN}$ system, the mainly side reaction is the hydrolysis of PO to propylene glycol (PG). On one hand, the generation of PG leads to the decrease of PO yield; on the other hand, the accumulated PG would adsorb on the active centers, resulting in the deactivation of catalyst. Apparently, it is necessary to inhibit the side reactions as well as to promote the epoxidation selectivity. BASF disclosed that adding trace amounts of potassium salt in the reactant mixture could significantly reduce the catalyst deactivation rate in HPPO process catalyzed by Ti-MWW-MeCN system $[37,38]$. However, the accumulation of potassium would poison the active Ti sites, causing irreversible deactivation and difficulty of regeneration. In our previous study, the PI-assisted structural rearrangement and fluorination treatment were performed on the formed Ti-MWW, respectively [16]. It was found that the structurally rearranged Ti-MWW extrudates exhibited the higher catalytic activity, and fluorination could inhibit the side reaction of PO hydrolysis to improve the stability of catalyst. In general, it is of great significance to develop high-performance applicable Ti-MWW zeolite and highly efficient HPPO process based on this Ti-MWW zeolite, which should be engineered delicately and comprehensively.

Herein, we present a controllable recrystallization strategy of extruded $\mathrm{SiO}_{2}$ /Ti-MWW catalyst by crystallizing the binders into MWW phase completely, with mechanical strength well preserved (Scheme 1). The obtained binder-free formed Ti-MWW zeolite exhibited superior activity and stability in 


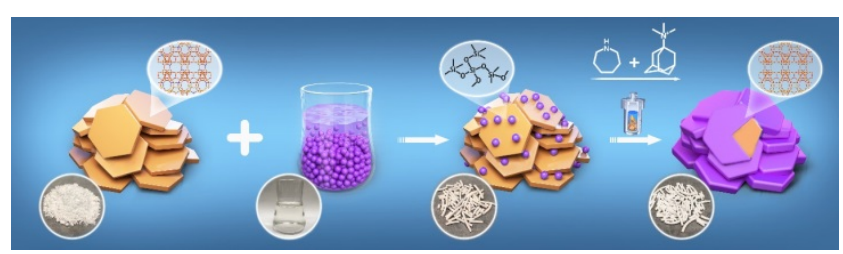

Scheme 1. The recrystallization process of shaped Ti-MWW catalyst.

HPPO process, and then its physicochemical properties were characterized in detail and correlated with the catalytic performance. Guided by the principles of increasing epoxidation reactivity as well as inhibiting side reactions, the microenvironments of active Ti sites of the binder-free Ti-MWW zeolite were chemically modified via successive PI and F treatments, so as to achieve a higher catalytic performance and an ultra-long lifetime of $2400 \mathrm{~h}$ in a single run.

\section{Experimental}

\subsection{Preparation of catalysts}

\subsubsection{Synthesis of Ti-MWW powder}

Following the procedures in the literature [39], Ti-MWW was hydrothermally synthesized from the gel of $1.0 \mathrm{SiO}_{2}: 1.4$ PI:0.67B $\mathrm{B}_{2} \mathrm{O}_{3}: 0.033 \mathrm{TiO}_{2}: 19.0 \mathrm{H}_{2} \mathrm{O}$. The as-made Ti-MWW layered precursor was refluxed in $2.0 \mathrm{M} \mathrm{HNO}_{3}$ aqueous solution to remove extra-framework Ti species and most of the framework B species. Finally, the acid-treated product was calcined at $823 \mathrm{~K}$ for $6 \mathrm{~h}$ to obtain the Ti-MWW powder with the Si/Ti ratio of 40 and $\mathrm{Si} / \mathrm{B}$ ratio of 97 , denoted as $\mathrm{P}-\mathrm{Ti}-\mathrm{MWW}$.

\subsubsection{Preparation of shaped Ti-MWW catalyst}

P-Ti-MWW (80 g), silica binders (30 wt\% colloidal silica, $66.7 \mathrm{~g}$ ) and sesbania powder (5 g) as pore generator were mixed homogeneously at ambient temperature. Then a certain amount of deionized water was added dropwise to into the homogeneous mixture to adjust the hardness of the final paste obtained by kneading. Subsequently, the paste was shaped into the uniform $\varnothing 1.8 \mathrm{~mm}$ strips by rapid extrusion model and dried at $393 \mathrm{~K}$ overnight. Finally, the extrudates were calcined at $823 \mathrm{~K}$ for $6 \mathrm{~h}$, named as S-Ti-MWW.

\subsubsection{Synthesis of binder-free Ti-MWW catalyst by recrystallization}

Binder-free Ti-MWW was synthesized by employing S-Ti-MWW as the precursor via recrystallization with HMI and $\mathrm{N}, \mathrm{N}, \mathrm{N}$-trimethyl-1-adamantammonium hydroxide (TMAdaOH) as dual SDAs. The S-Ti-MWW were mixed with the aqueous solution of two SDAs having a composition of 1.0 $\mathrm{SiO}_{2}: 0.1 \mathrm{TMAdaOH}: 0.12 \mathrm{HMI}: 7.0 \mathrm{H}_{2} \mathrm{O}$, where S-Ti-MWW was taken as pure silica phase. The mixture was then recrystallized at $423 \mathrm{~K}$ for $120 \mathrm{~h}$ under static conditions. After recrystallization, the extrudates were separated from the mixture by filtration, washed with deionized water, dried at $373 \mathrm{~K}$ overnight, and calcined at $823 \mathrm{~K}$ for $6 \mathrm{~h}$ to get the binder-free Ti-MWW, denoted as Bf-Ti-MWW.

\subsubsection{Chemical modification of binder-free Ti-MWW}

Firstly, the Bf-Ti-MWW extrudates were subject to the PI-assisted structural rearrangement according to the previous procedures [17]. The treatment was carried out at $443 \mathrm{~K}$ for 24 h statically with a molar composition of $1.0 \mathrm{SiO}_{2}: 1.0 \mathrm{PI}: 10.0 \mathrm{H}_{2} \mathrm{O}$. The PI-treated binder-free catalyst was washed with deionized water, dried at $393 \mathrm{~K}$ overnight and calcined at $823 \mathrm{~K}$ for $6 \mathrm{~h}$. Then, it was further immersed in $\mathrm{NH}_{4} \mathrm{~F}$ methanol solution at $433 \mathrm{~K}$ for $4 \mathrm{~h}$ with the $\mathrm{NH}_{4} \mathrm{~F} / \mathrm{SiO}_{2}$ molar ratio of 0.025 and the solid/liquid mass ratio of 0.2 . The product was filtered, dried at $393 \mathrm{~K}$ overnight and calcined at $823 \mathrm{~K}$ for $6 \mathrm{~h}$, denoted as RF-Ti-MWW.

\subsection{Characterization methods}

Powder X-ray diffraction (XRD) patterns were recorded on a Rigaku Ultima IV diffractometer using Ni-filtered $\mathrm{Cu} K_{\alpha} \mathrm{X}$-ray source $(\lambda=1.541 \AA$ ). UV-Vis spectra were obtained on a PerkinElmer UV-Vis Lambda 35 spectrophotometer using pure Ba$\mathrm{SO}_{4}$ as a reference. Scanning Electron Microscopy (SEM) was performed on a Hitachi S-4800 scanning electron microscope and Transmission Electron Microscopy (TEM) images were carried out on a Tecnai G ${ }^{2}$ F30 instrument. The chemical compositions of catalysts were analyzed by Inductively Coupled Plasma-Atomic Emission Spectrometry (ICP-AES) on a Thermo IRIS Intrepid II XSP atomic emission spectrometer after dissolving the samples in $40 \mathrm{wt} \%$ hydrofluoric acid aqueous solution. The $\mathrm{N}_{2}$ and $\mathrm{H}_{2} \mathrm{O}$ physisorption measurements were performed on a BEL SORP instrument at 77 and $298 \mathrm{~K}$, respectively. Prior to measurements, all the fresh catalysts were degassed at $623 \mathrm{~K}$ for $12 \mathrm{~h}$ under vacuum, while the deactivated catalyst was evacuated at $473 \mathrm{~K}$ for $12 \mathrm{~h}$. The total pore volume was determined at $p / p_{0}$ of 0.99 . The specific surface area and micropore volume were calculated by the Langmuir and $t$-plot method, respectively. The mesopore size volume was derived from $\mathrm{N}_{2}$ desorption data by BJH method. The CHN chemical analysis was carried out on an Elementar Vario III instrument. The organic contents of catalysts were determined in a thermogravimetric (TG) analysis on a METTLER TOLEDO TGA/SDTA 851 apparatus from 303 to $1073 \mathrm{~K}$ at a heating rate of $10 \mathrm{~K} \mathrm{~min}^{-1}$ in air. Fourier transform infrared spectra (FT-IR) were recorded on a Nicolet Nexus 670 FT-IR spectrometer at a resolution of $2 \mathrm{~cm}^{-1}$. The spectra in the framework vibration region and in the hydroxyl stretching region were collected after evacuation at $723 \mathrm{~K}$ for $3 \mathrm{~h}$. The natures of acid sites were characterized through in situ FT-IR spectra with pyridine (Py), $\mathrm{D}_{3}$-acetonitrile $\left(\mathrm{CD}_{3} \mathrm{CN}\right)$ and pivalonitrile as a probe molecule, respectively. A self-supported wafer $(30 \mathrm{mg}, 18 \mathrm{~mm}$ in diameter) was placed into an IR cell equipped with a vacuum system and pre-treated at $723 \mathrm{~K}$ for $2 \mathrm{~h}$. After pre-treatment, it was exposed to the vapor of probe molecules at room temperature for $15 \mathrm{~min}$ and the adsorbed probe molecules were subsequently desorbed by evacuation at different temperatures for 10 min. The solid-state MAS NMR spectra were collected on a VARIAN VNMRS-400 MB NMR spectrometer. The ${ }^{13} \mathrm{C}$ and ${ }^{29} \mathrm{Si}$ MAS NMR spectra were measured using a $7.5 \mathrm{~mm}$ T3HX probe and the ${ }^{19} \mathrm{~F}$ MAS NMR spectra were acquired by using a $2.5 \mathrm{~mm}$ 
HX-MAS probe. The X-ray photoelectron spectroscopy (XPS) was measured on the Kratos AXIS Supra equipment. The mechanical strength of shaped catalyst was measured on a DL-3 Particle Strength Tester.

\subsection{Evaluation of catalytic performance}

\subsubsection{Batchwise propylene epoxidation}

All the shaped catalysts used in the batchwise reaction were ground to powder to eliminate the diffusion constrains. In a typical run, 0.03 g catalyst, 0.03 mol $\mathrm{H}_{2} \mathrm{O}_{2}$ (30 wt $\%$ aqueous solution) and $10 \mathrm{~mL}$ MeCN were added into a stainless-steel autoclave reactor equipped with a Teflon-inner. The propylene was then kept into the reactor at a constant pressure of 0.4 $\mathrm{MPa}$, after purging the air inside by propylene for three times. After stirring vigorously at $313 \mathrm{~K}$ for $1 \mathrm{~h}$, the reactor was cooled down with ice water and then depressurized slowly. The reaction solution was separated for GC and titration analysis.

\subsubsection{Continuous liquid-phase propylene epoxidation}

The continuous liquid-phase propylene epoxidation was operated in a fixed-bed reactor that was immersed in a water bath to control the reaction temperature (Scheme S2). The catalyst was crushed and sieved to be 40-80 mesh, $3.0 \mathrm{~g}$ of which was loaded into a stainless-steel reactor tube (inner diameter of $10 \mathrm{~mm}$ ). Propylene was kept liquified at reaction temperatures by pressing nitrogen at pressures of 2.0-3.0 MPa. After the reaction temperature and pressure both reached the desirable values and kept stable, the propylene and the $\mathrm{MeCN} / \mathrm{H}_{2} \mathrm{O}_{2} / \mathrm{H}_{2} \mathrm{O}$ mixture solution were fed into the reactor independently by two dual-plunger pumps, which were premixed before being introduced into the catalyst bed. After passing through the catalyst bed, the reaction mixture solution from the reactor outlet and decompression valve, containing unconverted reactants, solvent and products, was collected in a storage tank at room temperature and pressure. During the continuous reaction, the reaction mixture was collected at regular intervals for analysis.

\subsubsection{Products analysis}

The reaction products were analyzed by a Gas Chromatograph (Shimadzu 2014, FID detector, Rtx-Wax capillary column) and the obtained products were further confirmed by a GC-MS (Agilent 6890 series GC system, 5937 network mass selective detector). The remaining amount of $\mathrm{H}_{2} \mathrm{O}_{2}$ was determined by the titration method with $0.05 \mathrm{M} \mathrm{Ce}\left(\mathrm{SO}_{4}\right)_{2}$ aqueous solution.

\section{Results and discussion}

\subsection{Characterization of catalysts}

\subsubsection{The revolution of structure and textural properties in the recrystallization process}

The XRD patterns were employed to investigate the structure revolution in the recrystallization process. As shown in Fig. 1 , all the catalysts were free of impurity, possessing the MWW

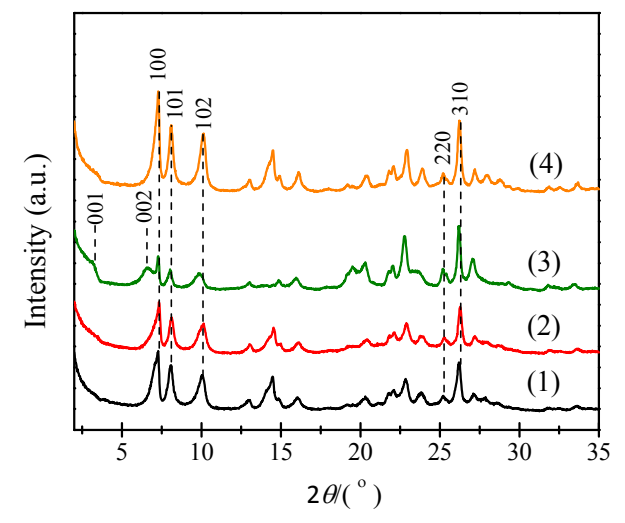

Fig. 1. XRD patterns of P-Ti-MWW (1), S-Ti-MWW (2), as-synthesized Bf-Ti-MWW (3) and calcined Bf-Ti-MWW (4).

topology and high crystallinity. Compared with the parent powder P-Ti-MWW, the diffraction peaks of shaped S-Ti-MWW sample decreased slightly in intensity due to the dilution effect of silica binder. After recrystallization, with the assistance of dual SDAs of HMI and TMAdaOH having different molecular dimensions, the as-synthesized binder-free Ti-MWW showed two newly developed diffraction peaks at $2 \theta$ of $3.5^{\circ}$ and $6.7^{\circ}$ attributed to the typical 001 and 002 reflections of the lamellar MWW along $c$-direction, and then the two characteristic peaks disappeared after subsequent calcination. The change of XRD patterns implied that the recrystallization of S-Ti-MWW transformed the 3-dinmensional (3D) crystalline structure into the corresponding 2D lamellar precursor, which was then converted into the 3D MWW structure again as a result of interlayer dehydration upon calcination. The calcined Bf-Ti-MWW sample showed more intensive diffraction peaks than S-Ti-MWW and even P-Ti-MWW, indicative of improved crystallinity by recrystallization. The observed structural transformation and enhancement of crystallinity were contributed by the crystallization of amorphous silica binder as well as the structural reorganization of Ti-MWW active component.

In addition, the ${ }^{13} \mathrm{C}$ MAS NMR spectrum confirmed that the TMAda $^{+}$and HMI were both incorporated into Bf-Ti-MWW structure and remained intact without decomposition in the recrystallization process (Fig. S1). The weight loss of SDAs (473-1000 K) was 19.7 wt\% (Fig. S2). And the C/N molar ratio in as-synthesized sample was 9.20 , which was between the theoretical values of $\mathrm{TMAda}^{+}(\mathrm{C} / \mathrm{N}=13)$ and $\mathrm{HMI}(\mathrm{C} / \mathrm{N}=6)$ molecules, and almost close to the actual composition added in recrystallization system $(\mathrm{C} / \mathrm{N}=9.18)$. These results implied that $\mathrm{TMAda}^{+}$and HMI participated and cooperated each other in the crystallization of amorphous silica into MWW phase.

The SEM images showed the differences in morphology of these catalysts (Fig. 2). The crystals of pristine P-Ti-MWW powder exhibited a typical plate-shaped morphology with a thickness of $\sim 100 \mathrm{~nm}$. For S-Ti-MWW, two separate phases were clearly observed, that is, plate-shaped Ti-MWW crystals and irregular binder silica nanoparticles. The Ti-MWW sheets stacked tightly together, and the irregular binder particles dispersed on the surface of Ti-MWW crystals. The binder phase totally disappeared upon recrystallization, with only tightly 

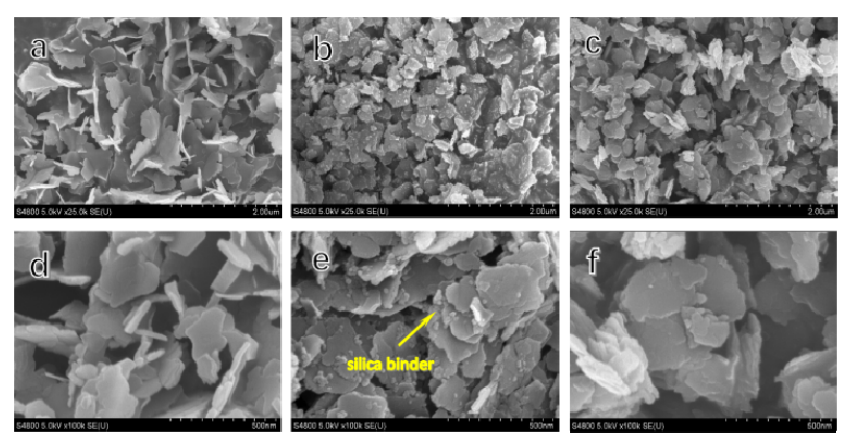

Fig. 2. SEM images of P-Ti-MWW (a,d), S-Ti-MWW (b,e), and Bf-TiMWW (c,f).
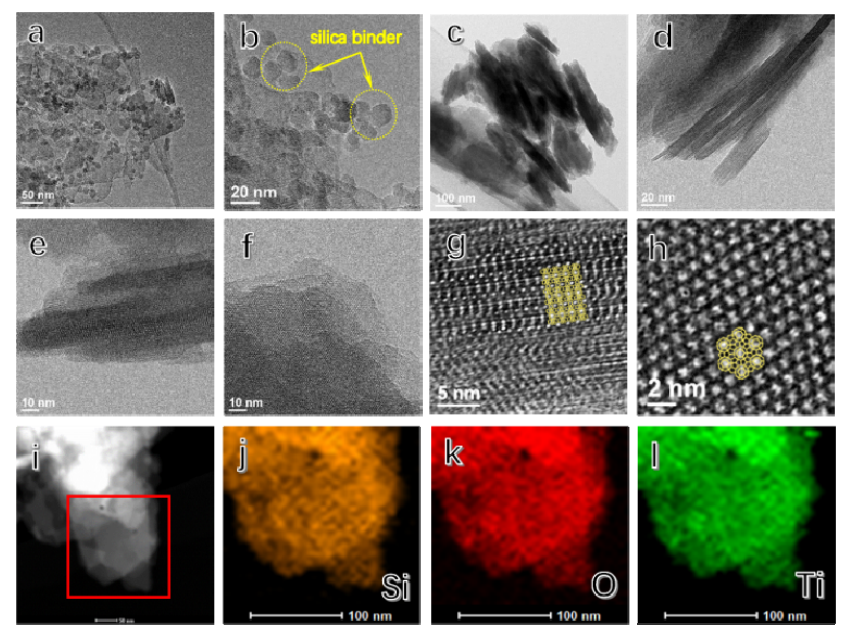

Fig. 3. HR-TEM images of S-Ti-MWW (a,b) and Bf-Ti-MWW (c-f); Edge-on TEM image of Bf-Ti-MWW taken along the directions of [100] (g) and [001] (h); STEM-HAADF image of Bf-Ti-MWW (i) and the corresponding EDX mapping images for $\mathrm{Si}, \mathrm{O}$ and Ti elements (j-l).

stacked sheet crystals remaining in Bf-Ti-MWW. Similarly, the TEM images showed that the amorphous binder particles adhered on the external surface of S-Ti-MWW crystals (Figs. $3(\mathrm{a}, \mathrm{b}))$, while all the binder particles disappeared in Bf-Ti-MWW, and the lattice fringes were clearly observed (Figs. 3(c)-(f)). Moreover, the HRTEM images verified that the structure of Bf-Ti-MWW crystals were fully consistent with the MWW topology along the $a$ and $c$ axis (Figs. 3(g,h)). The ele-
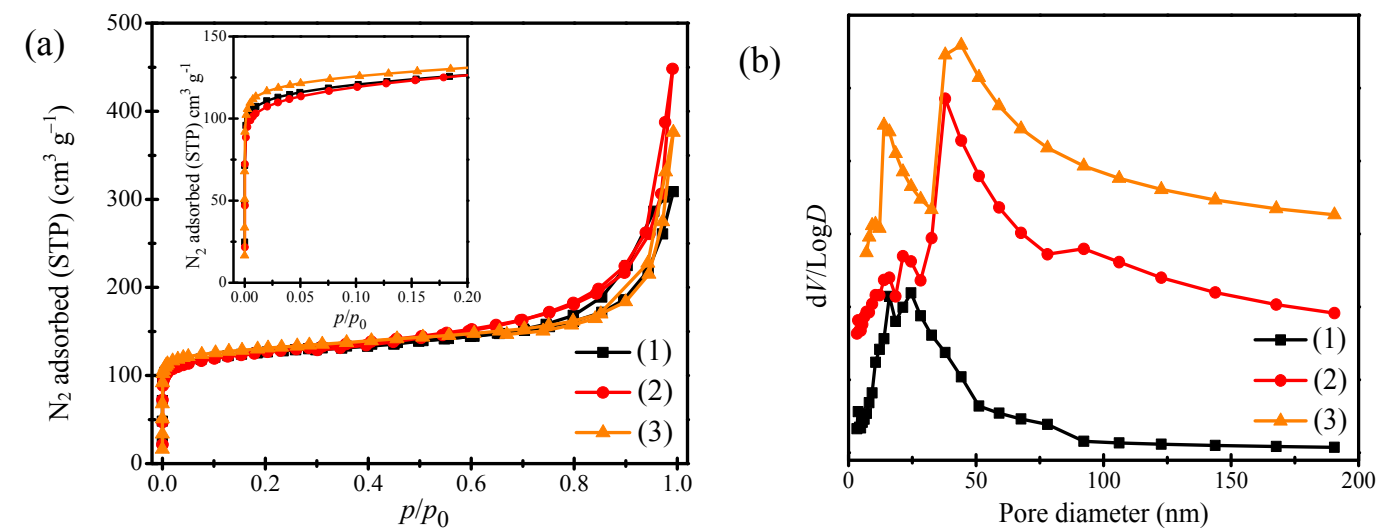

Fig. 4. (a) $\mathrm{N}_{2}$ adsorption-desorption isotherms at $77 \mathrm{~K}$; (b) BJH pore size distribution of P-Ti-MWW (1), S-Ti-MWW (2) and Bf-Ti-MWW (3). 
Table 1

Physicochemical properties and catalytic performance for the propylene epoxidation of various titanosilicate catalysts. ${ }^{\mathrm{a}}$

\begin{tabular}{|c|c|c|c|c|c|c|c|c|c|c|}
\hline \multirow{2}{*}{ Catalyst } & \multirow{2}{*}{$\mathrm{Si} / \mathrm{Ti}^{\mathrm{b}}$} & \multirow{2}{*}{$\mathrm{Si} / \mathrm{B}^{\mathrm{b}}$} & \multirow{2}{*}{$\begin{array}{c}\mathrm{SSA}^{\mathrm{c}} \\
/ \mathrm{m}^{2} \mathrm{~g}^{-1} \\
\end{array}$} & \multicolumn{2}{|c|}{ Pore volume $/ \mathrm{cm}^{3} \mathrm{~g}^{-1}$} & \multirow{2}{*}{$\begin{array}{l}\text { Mechanical strengthe } \\
\qquad / \mathrm{N} \mathrm{cm}^{-1}\end{array}$} & \multicolumn{2}{|c|}{$\mathrm{H}_{2} \mathrm{O}_{2} / \%$} & \multicolumn{2}{|c|}{$\mathrm{PO} / \%$} \\
\hline & & & & $V_{\text {mic. }}{ }^{\mathrm{d}}$ & $V_{\text {meso. }}$ & & conversion & $\overline{\text { efficiency }}$ & yield & selectivity \\
\hline P-Ti-MWW & 40 & 97 & 552 & 0.14 & 0.33 & - & 22.7 & 86.1 & 19.5 & 99.8 \\
\hline S-Ti-MWW & 53 & 128 & 507 & 0.12 & 0.56 & 13.2 & 15.2 & 86.3 & 13.1 & 99.9 \\
\hline Bf-Ti-MWW & 52 & 133 & 633 & 0.15 & 0.43 & 21.8 & 53.5 & 90.6 & 48.4 & 99.9 \\
\hline RF-Ti-MWW & 52 & 248 & 638 & 0.15 & 0.65 & 25.3 & 65.1 & 93.9 & 61.1 & 99.9 \\
\hline
\end{tabular}

a All the catalysts were grinded into powder for the batchwise propylene epoxidation. Reaction conditions: catalyst, $0.03 \mathrm{~g} ; \mathrm{H}_{2} \mathrm{O}_{2}$ ( 30 wt.\%), 0.03 mol; solvent MeCN, $10 \mathrm{~mL}$; temperature, $313 \mathrm{~K}$; time, $1 \mathrm{~h}$. ${ }^{\text {b }}$ Determined by ICP analysis. c Langmuir specific surface area (SSA) given by $\mathrm{N}_{2}$ adsorption isotherms at $77 \mathrm{~K}$. ${ }^{\mathrm{d}}$ Measured by $\mathrm{N}_{2}$ adsorption using $t$-plot method. e Average crushing strength of 25 grain extrudates in axial direction.
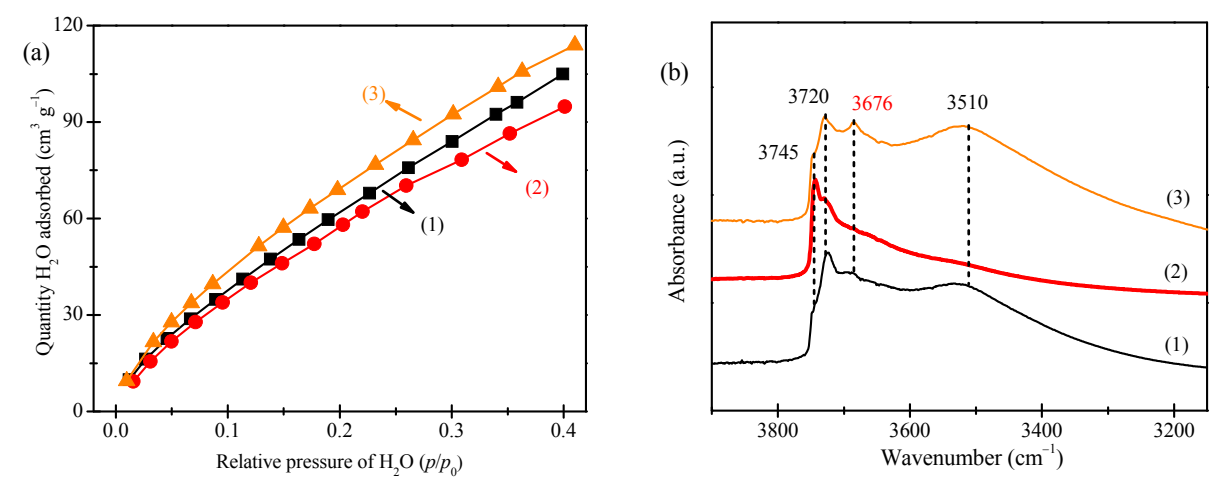

Fig. 5. (a) $\mathrm{H}_{2} \mathrm{O}$ adsorption isotherms at $298 \mathrm{~K}$; (b) FT-IR spectra in the region of hydroxyl stretching vibration for P-Ti-MWW (1), S-Ti-MWW (2) and Bf-Ti-MWW (3).

served macropore. Most importantly, the macroscopic body of catalyst extrudates remained, and their mechanical strength was significantly enhanced from 13.2 to $21.8 \mathrm{~N} \mathrm{~cm}^{-1}$ (Fig. S4 and Table 1). This might be contributed from improved intercrystalline interaction and regular arrangement of crystals [14]. Thus, the recrystallization eliminated the negative effects of binders on micropores of the extrudes and improved the porosity without destroying the macroscopic form of the extrudates, resulting in a binder-free Ti-MWW zeolite monolith with pure zeolitic phase.

\subsubsection{Difference in hydrophilicity/hydrophobicity}

The appropriate hydrophilicity/hydrophobicity of Ti-zeolites is a significant factor determining their catalytic activities [35,40]. The differences in hydrophilicity/hydrophobicity of the three catalysts were intuitively given by the $\mathrm{H}_{2} \mathrm{O}$ adsorption isotherms (Fig. 5(a)). In the range of $0<$ $p / p_{0}<0.4$, the $\mathrm{H}_{2} \mathrm{O}$ adsorption capacity declined in the order of Bf-Ti-MWW > P-Ti-MWW > S-Ti-MWW, but the difference was not very significant, indicating the hydrophilicity of Bf-Ti-MWW was slightly higher. This was also consistent with the experimental results of static $\mathrm{H}_{2} \mathrm{O}$ adsorption (Fig. S5). It was commonly believed that the zeolite materials that contained sufficient densities of the silanols like isolated $\equiv \mathrm{Si}-\mathrm{OH}$, gemini-type $=\mathrm{Si}-(\mathrm{OH})_{2}$ or hydroxyl nests $(\mathrm{Si}-\mathrm{OH})_{4}$ tend to adsorb $\mathrm{H}_{2} \mathrm{O}$ molecules via the stable hydrogen-bond interactions [41-43]. In the hydroxyl stretching region of IR spectra, the bands at 3745 , 3720,3676 and $3510 \mathrm{~cm}^{-1}$ were attributed to the external isolated $\mathrm{Si}-\mathrm{OH}$, internal $\mathrm{Si}-\mathrm{OH}, \mathrm{Ti}-\mathrm{OH}$ and $(\mathrm{Si}-\mathrm{OH})_{4}$, respectively [44]. As shown in Fig. 5(b), compared with P-Ti-MWW, the band at $3745 \mathrm{~cm}^{-1}$ became more intense for S-Ti-MWW because of the introduction of amorphous silica binders, whereas the bands at 3720 and $3510 \mathrm{~cm}^{-1}$ clearly decreased probably due to the condensation of $\mathrm{Si}-\mathrm{OH}$ during extrusion and subsequent calcination. However, in the case of Bf-Ti-MWW, the $3745 \mathrm{~cm}^{-1}$ band significantly diminished, indicating the recrystallization of the silica binder. Meanwhile, the 3720 and 3510 $\mathrm{cm}^{-1}$ bands became more intense, and an obvious band at 3676 $\mathrm{cm}^{-1}$ was observed. This meant that the Si-O-Ti and Si-O-Si bonds inside the Ti-MWW matrix were partially destroyed in the recrystallization process, forming a large number of $\mathrm{Ti}-\mathrm{OH}$, internal $\mathrm{Si}-\mathrm{OH}$ and $(\mathrm{Si}-\mathrm{OH})_{4}$ groups. More importantly, it suggested that Bf-Ti-MWW was hydrophilic in the inner space, while its exterior surface was relatively hydrophobic. The changes of Si defects were further estimated from the $Q^{3} / Q^{4}$

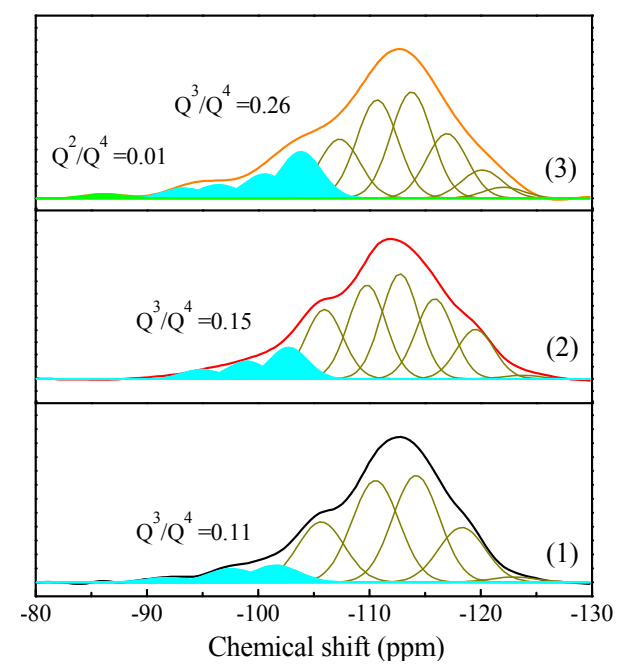

Fig. 6. ${ }^{29} \mathrm{Si}$ MAS NMR spectra of P-Ti-MWW (1), S-Ti-MWW (2) and Bf-Ti-MWW (3). 

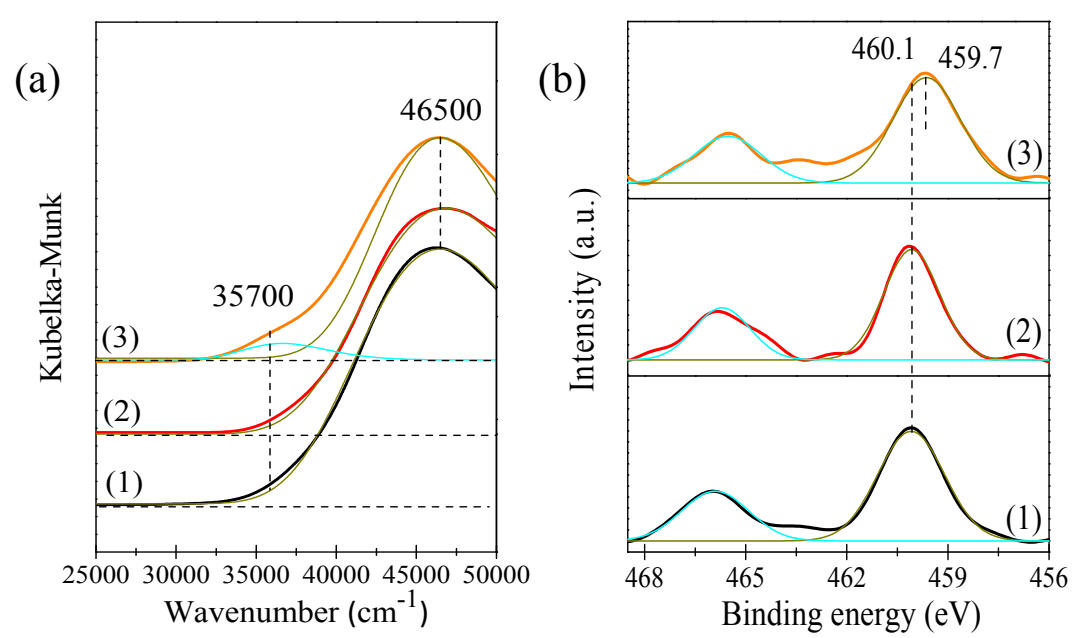

Fig. 7. UV-Vis spectra (a) and Ti $2 p$ XPS spectra (b) of P-Ti-MWW (1), S-Ti-MWW (2) and Bf-Ti-MWW (3).

group ratio in ${ }^{29} \mathrm{Si}$ MAS NMR spectra (Fig. 6). The $\mathrm{Q}^{3} / \mathrm{Q}^{4}$ ratio of S-Ti-MWW (0.15) was greater than that of P-Ti-MWW (0.11) due to the presence of amorphous silica binder in the former sample. However, the $\mathrm{H}_{2} \mathrm{O}$ adsorption capacity of S-Ti-MWW was weaker than P-Ti-MWW, probably due to the blocking the micropores by the silica binder. The $\mathrm{Q}^{3} / \mathrm{Q}^{4}$ ratio increased significantly from 0.15 for S-Ti-MWW up to 0.26 for Bf-Ti-MWW, indicating the existence of more $\mathrm{Si}(\mathrm{OH})(\mathrm{OSi})_{3}$ species in the latter one. And an additional tiny $\mathrm{Q}^{2}$ peak was detected as well, where the $Q^{2} / Q^{4}$ ratio was 0.01 , suggesting the existence of a small amount of $\mathrm{Si}(\mathrm{OH})_{2}(\mathrm{OSi})_{2}$ species. Notably, the $\mathrm{Q}^{3} / \mathrm{Q}^{4}$ ratio of Bf-Ti-MWW (0.26) was also greater than that of P-Ti-MWW (0.11), signifying the presence of more Si defects in the former one. However, no obvious holes or hollow structures were ob- served in the crystals as evidenced by the TEM images of Bf-Ti-MWW. It could be presumed that only a small part of Si species in the matrix was dissolved to participate in the transformation of silica binders to zeolite phase. Moreover, it was found that the $\mathrm{H}_{2} \mathrm{O}_{2}$ molecules were enriched effectively in the Bf-Ti-MWW due to its superior internal hydrophilicity (Fig. S6). This would be beneficial for improving the oxidation activity of Ti sites in $\mathrm{H}_{2} \mathrm{O}_{2}$-involved reactions.

\subsubsection{Characterization of Ti active sites}

It could be determined that recrystallizing the shaped catalyst S-Ti-MWW would not cause the loss of Ti active components, as the $\mathrm{Si} / \mathrm{Ti}$ ratio was maintained at 52-53 (Table 1). In UV-Vis spectra (Fig. 7(a)), all the catalysts showed a main band

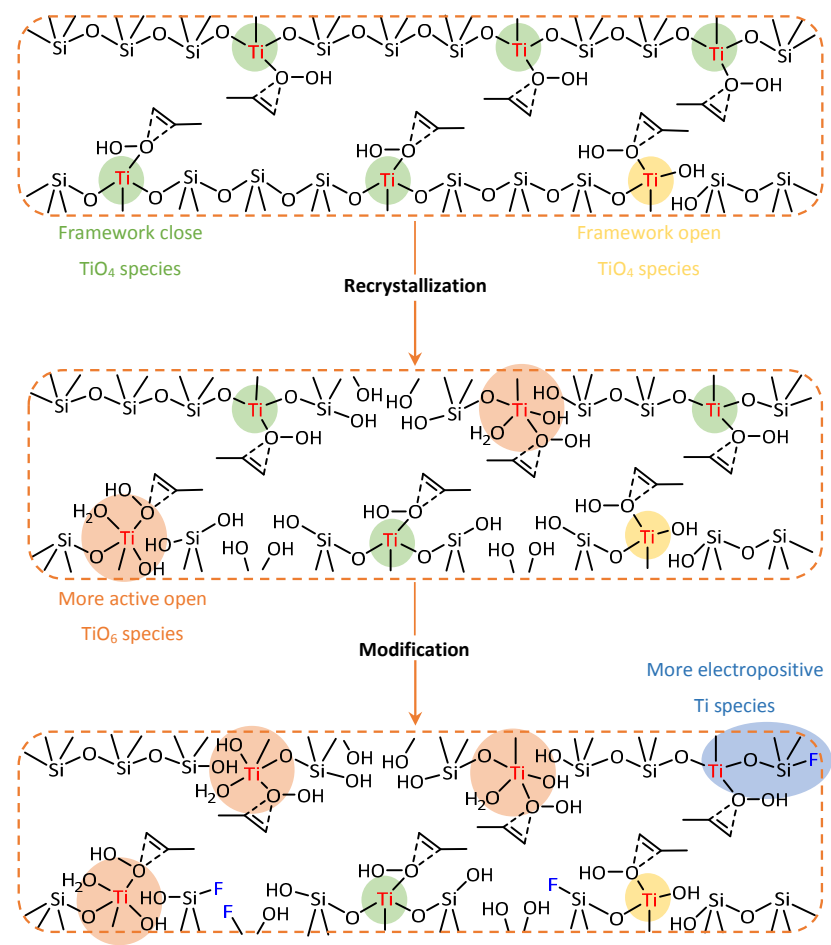

Scheme 2. The possible changes of active Ti sites during recrystallization and subsequence modification of microenvironments of Ti active sites. 
at about $46500 \mathrm{~cm}^{-1}(215 \mathrm{~nm})$, which was assigned to the framework tetra-coordinated $\mathrm{Ti}$ species $\left(\mathrm{TiO}_{4}\right)$ [45]. However, for Bf-Ti-MWW, a weak shoulder band appeared at about $35700 \mathrm{~cm}^{-1}(280 \mathrm{~nm})$, ascribed to the open hexa-coordinated Ti species $\left(\mathrm{TiO}_{6}\right)$ in the framework $[17,27]$, and the percentage of this band was approximately $8.7 \%$. It indicated that in the recrystallization process, the partial Si dissolution in the matrix converted a small part of $\mathrm{TiO}_{4}$ species into the open $\mathrm{TiO}_{6}$ ones (Scheme 2). In addition, the absence of the band at 38500 and $30300 \mathrm{~cm}^{-1}(260$ and $330 \mathrm{~nm})$ also ruled out the formation of extra-framework hexa-coordinated Ti fragments and anatase $[28,46,47]$. Consistently, all the catalysts had an obvious characteristic band at $960 \mathrm{~cm}^{-1}$ in FT-IR spectra (Fig. S7). At present, the precise attribution of this band is still controversial. Some researcheres attributed it to the stretching vibration of $\mathrm{Si}-\mathrm{O}$ bond affected by the neighbored Ti ions [48-50], while it was also assigned to the stretching vibration of Si-O-Ti in the [Ti(OSiO 3$\left.)_{4}\right]$ unit [51], which was normally taken as fingerprint of the incorporation of $\mathrm{Ti}$ species in the zeolite framework [51-53]. In addition, a weak shoulder IR band at about 930 $\mathrm{cm}^{-1}$ related to the tripodal $\mathrm{Ti}(\mathrm{OSi})_{3} \mathrm{OH}$ species could also been observed for all the samples, evidencing the presence of open framework $\mathrm{TiO}_{4}$ species [30]. Furthermore, the electronic states of Ti species were investigated by XPS spectra. As shown in Fig. 7 (b), the binding energy (BE) of Ti $2 p_{3 / 2}$ was unchanged at $460.1 \mathrm{eV}$ after shaping. However, the $\mathrm{BE}$ of $\mathrm{Ti} 2 p_{3 / 2}$ reduced from $460.1 \mathrm{eV}$ for S-Ti-MWW to $459.7 \mathrm{eV}$ for Bf-Ti-MWW, which revealed the charge distribution of partial Ti ions became more negative. As depicted in Scheme 2, this was attributed to the formation of open $\mathrm{TiO}_{6}$ species $\left(\mathrm{Ti}(\mathrm{OH})_{2}(\mathrm{OSi})_{2}\left(\mathrm{H}_{2} \mathrm{O}\right)_{2}\right)$.

\subsubsection{Difference in acid properties}

The unsaturated tetra-coordinated $\mathrm{Ti}$ species in the Ti-zeolite framework exhibit Lewis acid properties due to its ability to accept lone pair electrons. It could preferentially adsorb $\mathrm{H}_{2} \mathrm{O}_{2}$ and coordinate with it to form Ti-OOH intermediate, and further interact with alkene substrates to realize the transfer of oxygen, thus completing the selective oxidation. $\mathrm{CD}_{3} \mathrm{CN}$ is an efficient and sensitive probe molecule to characterize the acid properties of Ti-zeolite, especially the Lewis acid sites (LAS) [54]. The absorption band at $2302 \mathrm{~cm}^{-1}$ was attributed to the $v(\mathrm{C} \equiv \mathrm{N})$ of $\mathrm{CD}_{3} \mathrm{CN}$ molecules bonded to the framework Lewis acidic Ti atoms, whereas the band at 2274 $\mathrm{cm}^{-1}$ was assigned to the $v(\mathrm{C} \equiv \mathrm{N})$ adsorbed to silanol (Si-OH and $\left.(\mathrm{Si}-\mathrm{OH})_{4}\right)$ groups, respectively [35]. And the bands at 2215 and $2115 \mathrm{~cm}^{-1}$ were related to the $v_{\text {as }}\left(\mathrm{CD}_{3}\right)$ and $v_{\mathrm{s}}\left(\mathrm{CD}_{3}\right)$, respectively. As shown in Figs. 8(a)-(c), with increase of the temperature, all the bands in the three catalysts decreased rapidly. Meanwhile, the $2302 \mathrm{~cm}^{-1}$ band became more obvious. And the 2302
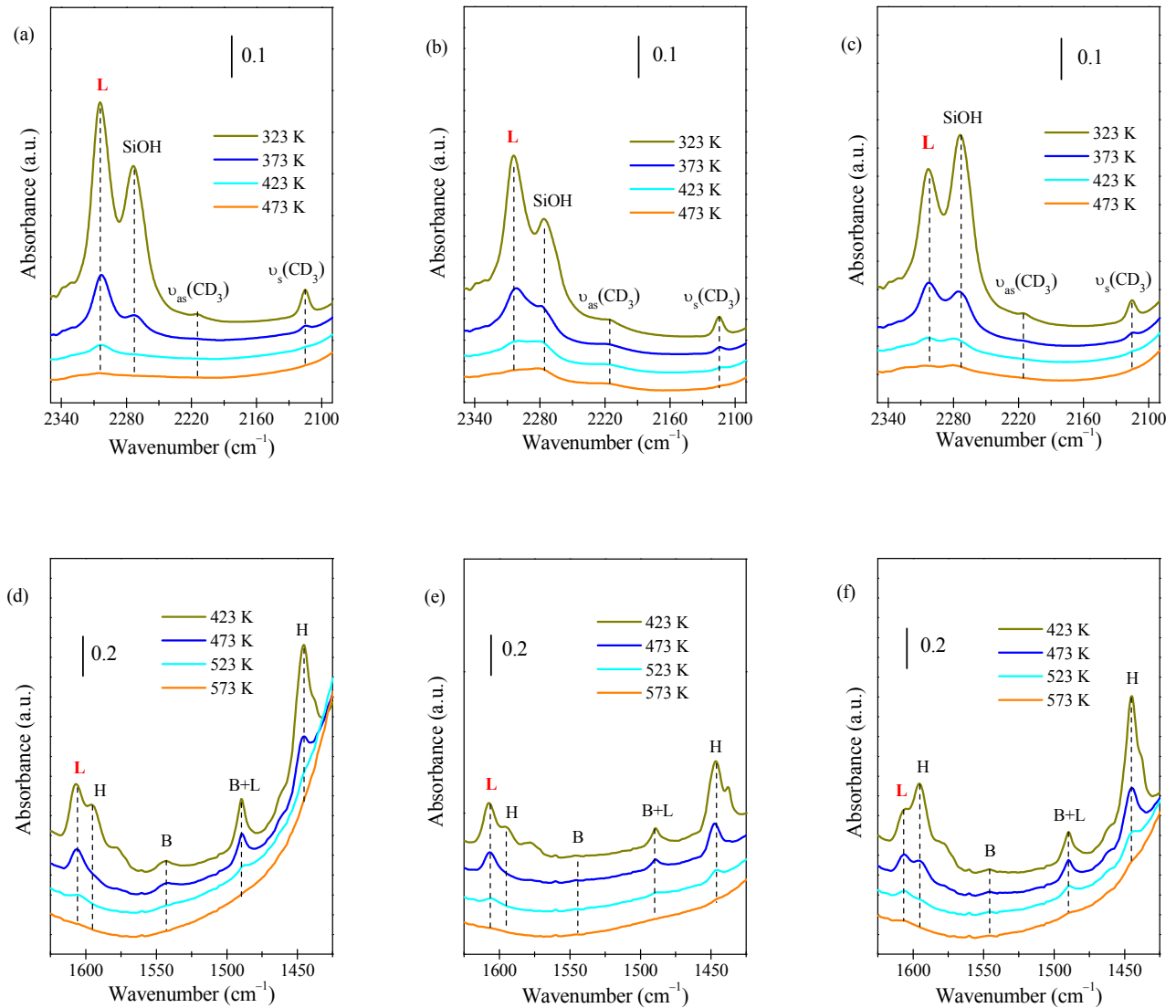

Fig. 8. $\mathrm{CD}_{3} \mathrm{CN}(\mathrm{a}-\mathrm{c})$ or pyridine (d-f) adsorbed FT-IR spectra of P-Ti-MWW (a,d), S-Ti-MWW (b,e) and Bf-Ti-MWW (c,f) after evacuation at different temperatures. B: Brönsted acid sites; L: Lewis acid sites; H: hydrogen-bonded pyridine. 
$\mathrm{cm}^{-1}$ band of P-Ti-MWW was higher than that of S-Ti-MWW and Bf-Ti-MWW at the same desorption temperature due to the higher Ti content in P-Ti-MWW. Notably, the $2274 \mathrm{~cm}^{-1}$ band of Bf-Ti-MWW was always higher than that of P-Ti-MWW and S-Ti-MWW regardless of the desorption temperature, indicating that Bf-Ti-MWW possessed more internal crystallographic defects. The pyridine (Py)-adsorbed FT-IR spectra were also employed to measure the acid properties semi-quantitatively (Figs. 8(d)-(f)). The bands at 1598 and $1446 \mathrm{~cm}^{-1}$ were both attributed to the hydrogen-bonded pyridine [55]. And the characteristic IR bands at 1545 and $1606 \mathrm{~cm}^{-1}$ were assigned to pyridine adsorbed to the Brönsted acid sites (BAS) and LAS, respectively. The band at $1490 \mathrm{~cm}^{-1}$ was attributed to the mix of BAS and LAS. The Py-adsorbed IR spectra confirmed that Bf-Ti-MWW had both LAS and BAS, wherein the presence of BAS could result from the residual boron in the silica matrix. Compared with S-Ti-MWW, the 1598 and $1446 \mathrm{~cm}^{-1}$ bands of Bf-Ti-MWW were higher at different desorption temperature, especially for the $1598 \mathrm{~cm}^{-1}$ band, implying more hydroxyl groups in Bf-Ti-MWW. For all the catalysts, the band at 1606 $\mathrm{cm}^{-1}$ diminished gradually upon evacuation at elevated temperatures. However, in the case of Bf-Ti-MWW, a weak band at $1606 \mathrm{~cm}^{-1}$ could still be observed after desorption at $573 \mathrm{~K}$, while it was vanished for P-Ti-MWW and S-Ti-MWW, indicating that Bf-Ti-MWW had the stronger LAS. This was due to the presence of $\mathrm{Ti}-\mathrm{OH}$ in $\mathrm{TiO}_{6}$ species could increase the acidity of the Ti-zeolite [27]. In addition, the bulky pivalonitrile-adsorbed IR spectra were employed to measure the accessibility of LAS in the monolithic Ti-MWW qualitatively. Bf-Ti-MWW exhibited a characteristic band at $2308 \mathrm{~cm}^{-1}$ in the pivalonitrile-adsorbed IR spectra (Fig. S8) at lower desorption temperature, which was related to the LAS [56]. It demonstrated the accessibility of active Ti sites, even though they were enclosed within the monolith.

\subsection{Performance in catalyzing the propylene epoxidation}

\subsubsection{A comparison of catalytic performance before and after recrystallization}

The catalytic performance of the three catalysts were firstly investigated in the batchwise epoxidation of propylene. Reasonably, the $\mathrm{H}_{2} \mathrm{O}_{2}$ conversion and $\mathrm{PO}$ yield decreased from $22.7 \%$ and $19.5 \%$ for P-Ti-MWW to $15.2 \%$ and $13.1 \%$ for S-Ti-MWW, respectively (Table 1). However, the $\mathrm{H}_{2} \mathrm{O}_{2}$ conversion and $\mathrm{PO}$ yield of Bf-Ti-MWW were surprisingly increased to $53.5 \%$ and $48.4 \%$, respectively. And the $\mathrm{H}_{2} \mathrm{O}_{2}$ utilization efficiency was also increased slightly, reaching up to $90.6 \%$. In-situ site titration with methylphosphonic acid (MPA) was used to
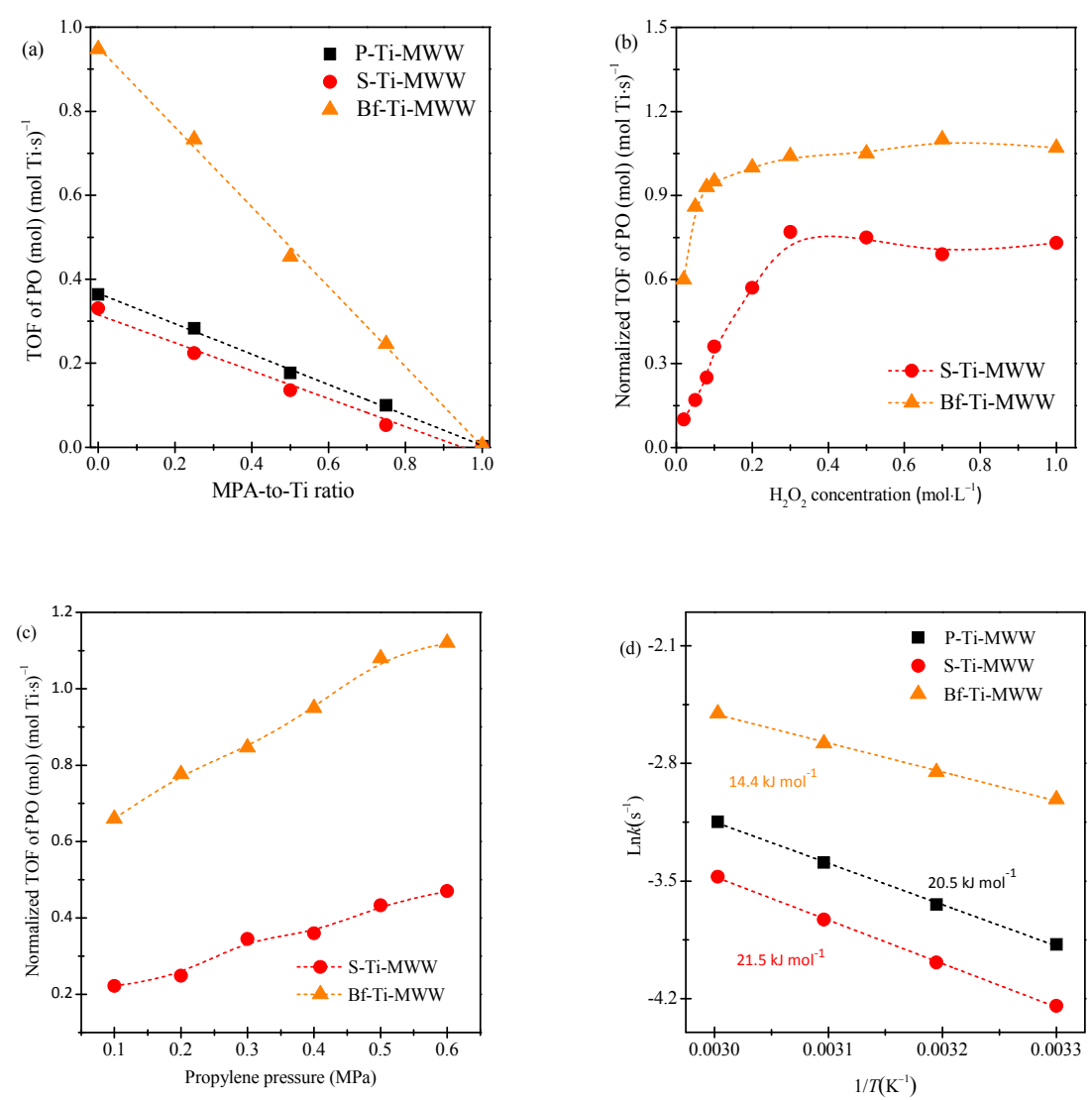

Fig. 9. Dependence of turnover frequency of $\mathrm{PO}$ on methylphosphonic acid (MPA)-to-Ti ratio $\left(\mathrm{H}_{2} \mathrm{O}_{2} 0.1 \mathrm{~mol} \mathrm{~L} \mathrm{~L}^{-1}, \mathrm{C}_{3} \mathrm{H}_{6} 0.4 \mathrm{MPa}\right.$, solvent MeCN, temperature $313 \mathrm{~K})(\mathrm{a}), \mathrm{H}_{2} \mathrm{O}_{2}$ concentration $\left(\mathrm{C}_{3} \mathrm{H}_{6} 0.4 \mathrm{MPa}\right.$, solvent $\mathrm{MeCN}$, temperature $\left.313 \mathrm{~K}\right)$ (b) and $\mathrm{C}_{3} \mathrm{H}_{6}$ pressure $\left(\mathrm{H}_{2} \mathrm{O}_{2} 1.0\right.$ mol L-1, solvent MeCN, temperature $313 \mathrm{~K}$ ) (c) over various catalysts; Kinetic curves fitted by Arrhenius equation in propylene epoxidation (d). 
determine the number of active Ti sites available in various Ti-zeolites [57]. Epoxidations were performed at different ratios of MPA-to-Ti where the value of MPA-to-Ti that correspond to extrapolated turnover frequency (TOF) of zero were taken to be the fraction of available Ti in catalyst [57]. For all these catalysts, the TOF values of PO decreased linearly with the increase of MPA-to-Ti ratio (Fig. 9(a)), indicating that the MPA poisoned the active $\mathrm{Ti}$ sites for epoxidation. The available $\mathrm{Ti}$ sites in S-Ti-MWW was 94.8\%, lower than $99.3 \%$ of the P-Ti-MWW, suggesting that the introduced binders partially cover the micropore mouths of Ti-MWW so as to block some micropores, making some active sites existing inside these pores useless. After recrystallization, the fraction of available $\mathrm{Ti}$ sites was increased to $99.7 \%$, signifying the blocked micropores were reopened and the active sites within the pores were well accessible.

The TOF values of PO formation were normalized based on the available Ti species amounts in catalysts calculated by Fig. 9(a), and the normalized TOF value of powder Ti-MWW was approximately equivalent to that of the shaped one. Therefore, the changes of normalized TOF values with $\mathrm{H}_{2} \mathrm{O}_{2}$ concentration and propylene pressure were investigated only over the shaped and recrystallized catalyst, respectively. For both catalysts, the normalized TOF values of PO increased almost linearly with $\mathrm{H}_{2} \mathrm{O}_{2}$ at lower concentration (Fig. 9(b)), which indicated the active sites were unsaturated by the $\mathrm{H}_{2} \mathrm{O}_{2}$-derived species under this condition. The formation of $\mathrm{Ti}-\mathrm{OOH}$ intermediate is generally considered to be the rate-determining step for epoxidation reaction, while the transfer of active $0^{\alpha}$ is relatively rapid. It could be speculated that the epoxidation rate was mainly affected by the formation rate of Ti-OOH at lower $\mathrm{H}_{2} \mathrm{O}_{2}$ concentration. However, the TOF values leveled-off under higher $\mathrm{H}_{2} \mathrm{O}_{2}$ concentration because the formation rate of Ti-OOH did not increase once the majority of Ti active sites were occupied. When the $\mathrm{H}_{2} \mathrm{O}_{2}$ concentration was greater than $0.1 \mathrm{~mol} \mathrm{~L}^{-1}$, the TOF value of Bf-Ti-MWW became independent of $\mathrm{H}_{2} \mathrm{O}_{2}$ concentration, while for S-Ti-MWW, the TOF value was almost invariable at $\mathrm{H}_{2} \mathrm{O}_{2}$ concentration $>0.3 \mathrm{~mol} \mathrm{~L}^{-1}$. This meant that the active Ti sites in Bf-Ti-MWW could be saturated with the $\mathrm{H}_{2} \mathrm{O}_{2}$-derived species at the lower $\mathrm{H}_{2} \mathrm{O}_{2}$ concentration in comparison to S-Ti-MWW. Notably, the TOF values of Bf-Ti-MWW were always higher than that of S-Ti-MWW, especially at lower $\mathrm{H}_{2} \mathrm{O}_{2}$ concentration, indicating superior epoxidation activity. Combined with the above results, it could be concluded that the binder-free Ti-MWW monolith with internal hydrophilicity had excellent capacity of $\mathrm{H}_{2} \mathrm{O}_{2}$ enrichment and activation, which promoted the formation of Ti-OOH. Fig. 9(c) showed that the normalized TOF values of the two catalysts was positively correlated with propylene pressure, because increasing the pressure of propylene could improve its solubility in the solvent of MeCN. The normalized TOF values of Bf-Ti-MWW was always higher than that of S-Ti-MWW. The apparent activation energies $\left(E_{\mathrm{a}}\right)$ calculated by fitting the Arrhenius equation, were 20.5, 21.5 and $14.4 \mathrm{~kJ} \mathrm{~mol}^{-1}$ for P-Ti-MWW, S-Ti-MWW and Bf-Ti-MWW, respectively (Fig. 9(d)).

In a word, the intrinsic activity of Ti-MWW in respect to the activity of per Ti active site was significantly improved after recrystallization. This should be ascribed to the change of coordinated state of active Ti sites and the improvement of internal hydrophilicity after recrystallization. The constructed open framework $\mathrm{TiO}_{6}$ octahedron with stronger LAS showed a better ability to activate $\mathrm{H}_{2} \mathrm{O}_{2}[27,47]$. Besides, the existence of more internal Si-OH nests promoted the $\mathrm{H}_{2} \mathrm{O}_{2}$ accumulation within the micropores, favoring the generation of $\mathrm{Ti}-\mathrm{OOH}$ [36]. And the $\mathrm{Si}-\mathrm{OH}$ nests anchored nearby active sites would disrupt the epoxidation transition states by $\mathrm{H}$-bonded $\mathrm{H}_{2} \mathrm{O}$ clusters, which may produce entropy gains so as to increase epoxidation reactivity [35].

\subsubsection{A comparison of stability of Bf-Ti-MWW and S-Ti-MWW for continuous propylene epoxidation}

A long working life is the essential factor for a heterogeneous catalyst to be successfully applied in the actual industrial process. For both catalysts, an induction period was observed, where the PO yield and selectivity as well as $\mathrm{H}_{2} \mathrm{O}_{2}$ efficiency increased gradually and reached their maximum values (Fig. 10). And then they maintained unchanged until the deactivation stage of catalyst. The S-Ti-MWW catalyst gradually deactivated after running for $75 \mathrm{~h}$. Nevertheless, the lifetime of Bf-Ti-MWW reached $640 \mathrm{~h}$ under the same conditions, which was approximately 8.5 times that of S-Ti-MWW. It was also nearly twice as long as the longest lifetime that we previously reported [16]. And the $\mathrm{H}_{2} \mathrm{O}_{2}$ conversion and $\mathrm{PO}$ yield of Bf-Ti-MWW reached above $99.8 \%$ and $91.4 \%$, respectively, significantly higher than those of S-Ti-MWW $(98.3 \%$ and $87.2 \%$ ). Besides, the $\mathrm{H}_{2} \mathrm{O}_{2}$ efficiency of $\mathrm{Bf}-\mathrm{Ti}-\mathrm{MWW}$ was also increased to $>90.0 \%$. All these results demonstrated that Bf-Ti-MWW exhibited superior epoxidation activity as well stability, with great potential in practical application.

\subsection{Modification of the microenvironment of active Ti sites in Bf-Ti-MWW}

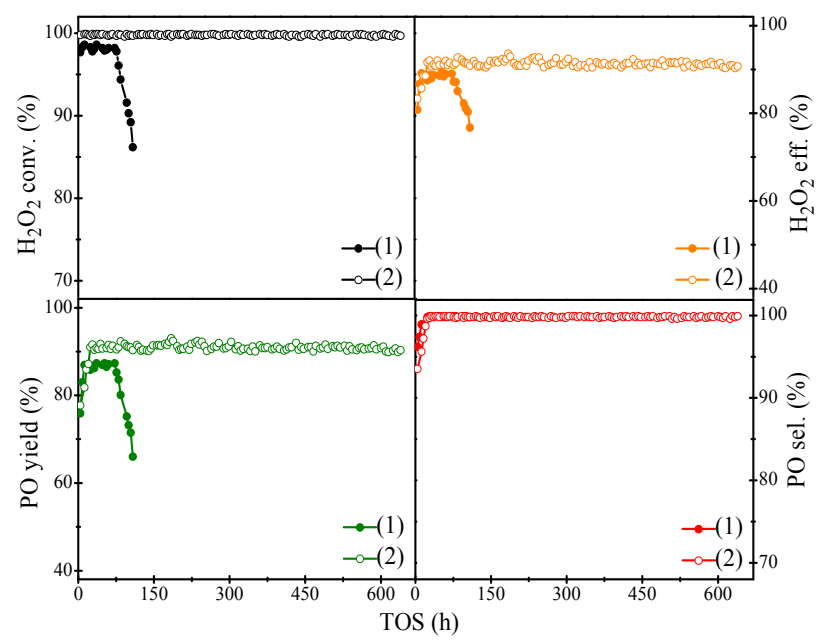

Fig. 10. Comparison of the lifetime of S-Ti-MWW (1 solid) and Bf-Ti-MWW (2, blank). Reaction conditions: $\mathrm{C}_{3}=/ \mathrm{H}_{2} \mathrm{O}_{2}$ ratio $=3,313 \mathrm{~K}, 2$ $\mathrm{MPa}, \operatorname{WHSV}\left(\mathrm{H}_{2} \mathrm{O}_{2}\right)=0.3 \mathrm{~h}^{-1}, \operatorname{WHSV}(\mathrm{MeCN})=6.5 \mathrm{~h}^{-1}, \operatorname{WHSV}\left(\mathrm{H}_{2} \mathrm{O}\right)=0.7$ $\mathrm{h}^{-1}$. 


\subsubsection{Characterization of the modified Bf-Ti-MWW}

Although the obtained binder-free Ti-MWW zeolite had shown outstanding catalytic performance in HPPO process, it still had some problems that cannot be ignored. The framework $\mathrm{TiO}_{6}$ species exhibited better catalytic activity in epoxidation than $\mathrm{TiO}_{4}$ species, but the increase of coordination number led to the increase of the electronegativity of Ti sites, which was negative for the transfer of active $0^{\alpha}$. Besides, it was generally accepted that the side reaction of PO hydrolysis depended on the acid sites derived from $\mathrm{Ti}-\mathrm{OH}, \mathrm{Si}-\mathrm{OH}$ and $\mathrm{Ti}-\mathrm{OOH}$ species in the Ti-zeolite $/ \mathrm{H}_{2} \mathrm{O}_{2}$ catalytic system [16]. A large amount of $\mathrm{Si}-\mathrm{OH}$ in Bf-Ti-MWW might potentially promote the hydrolysis of PO, leading to the decrease in selectivity and stability. Guided by the principles of increasing epoxidation reactivity as well as inhibiting side reaction, the microenvironments of active $\mathrm{Ti}$ sites of binder-free Ti-MWW zeolite were further chemically modified via successive PI and F treatments.

After modification, there was no obvious change in crystallinity (Fig. 11(a)), Ti content (Table 1) and morphology (Fig. S9). The micropore volume remained unchanged, while the specific surface area, mesopore volume and mechanical strength were increased (Fig. 11(b) and Table 1), due to the modification-induced slight desilication and the further improvement of intercrystalline interaction $[14,16]$. RF-Ti-MWW possessed both the $\mathrm{TiO}_{4}$ and open $\mathrm{TiO}_{6}$ species, while the ratio of $\mathrm{TiO}_{6}$ species increased from $8.7 \%$ to $14.5 \%$ after modification (Fig. 11(c)). And the characteristic IR bands at 960 and 930 $\mathrm{cm}^{-1}$ were also observed in RF-Ti-MWW (Fig. S10). In the ${ }^{19} \mathrm{~F}$ MAS NMR spectrum of RF-Ti-MWW, three F related resonances were observed at $-163,-155$ and -118 ppm (Fig. 11(d)) as- signed to the $\mathrm{B}-\mathrm{F}, \mathrm{SiO}_{3 / 2} \mathrm{~F}$ and $\mathrm{SiF}_{6}{ }^{2-}$ species, respectively [31], as graphically shown in Scheme 2. Moreover, the modification increased the BE of Ti $2 p_{3 / 2}$ from $459.7 \mathrm{eV}$ for Bf-Ti-MWW to $460.0 \mathrm{eV}$ for RF-Ti-MWW (Fig. 11(e)), implying the charge distribution of the Ti sites in RF-Ti-MWW became more positive. It could be attributed to the electron-withdrawing inductive effect of the $\mathrm{F}$ in the formed $\mathrm{SiO}_{3 / 2} \mathrm{~F}$ species connected to the framework Ti species [32]. As shown in Fig. 11(f), the resonance assigned to $\mathrm{Q}^{2}$ configuration $(<-95 \mathrm{ppm})$ was disappeared completely in RF-Ti-MWW. Meanwhile, the $\mathrm{Q}^{3} / \mathrm{Q}^{4}$ ratio reduced from 0.26 for $\mathrm{Bf}-\mathrm{Ti}-\mathrm{MWW}$ to 0.19 for RF-Ti-MWW, indicating that the Si defect sites were reduced after modification. Compared with Bf-Ti-MWW, the IR bands at 3510 and $3745 \mathrm{~cm}^{-1}$ of RF-Ti-MWW were significantly diminished, especially the $3745 \mathrm{~cm}^{-1}$ band (Fig. S11). On one hand, during the PI treatment, the framework of Ti-MWW zeolite was rearranged reversibly, in which the migration of $\mathrm{Si}$ into the hydroxyl nests or partial dehydroxylation of adjacent $\mathrm{Si}-\mathrm{OH}$ groups to form a Si-O-Si linkage occurred [58]. On the other hand, a large portion of $\mathrm{Si}-\mathrm{OH}$ groups interacted with the $\mathrm{F}$ species to form the $\mathrm{Si}-\mathrm{F}$ species during fluorination modification. However, the 3676 and $3720 \mathrm{~cm}^{-1}$ bands were maintained due to the presence of $\mathrm{Ti}-\mathrm{OH}$ and internal Si-OH groups. In addition, the LAS of the catalyst was enhanced after modification (Figs. S12 and S13), which was presumed to result from the presence of $\mathrm{Ti}-\mathrm{OH}$ and the improved electropositivity of the Ti sites in the silica matrix.

\subsubsection{Catalytic performance of RF-Ti-MWW catalyst}

The epoxidation reactivity of the modified catalyst was first
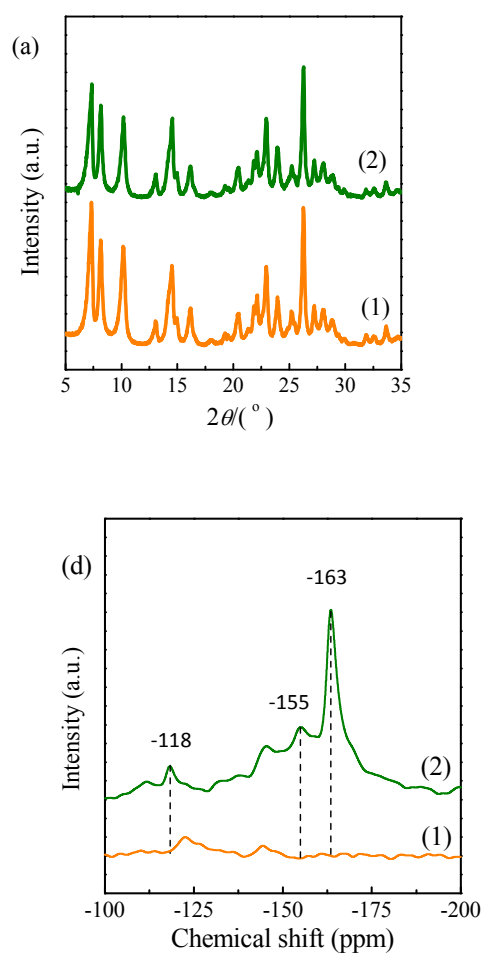
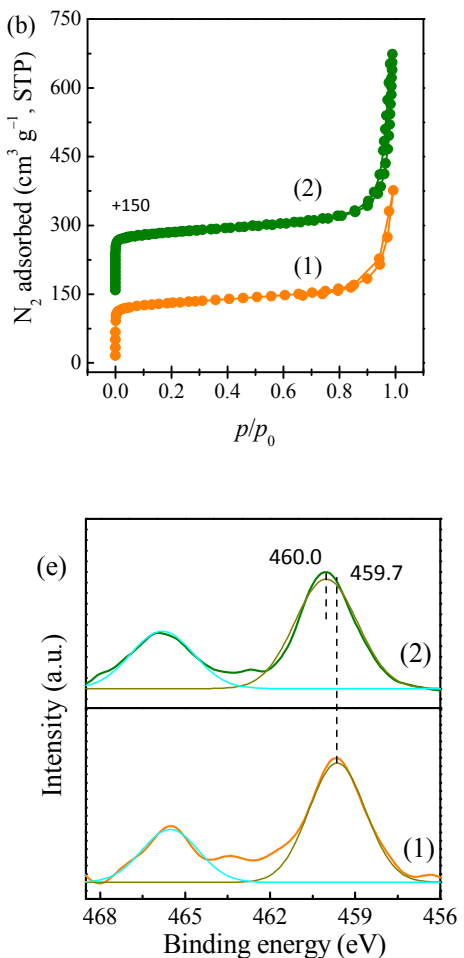
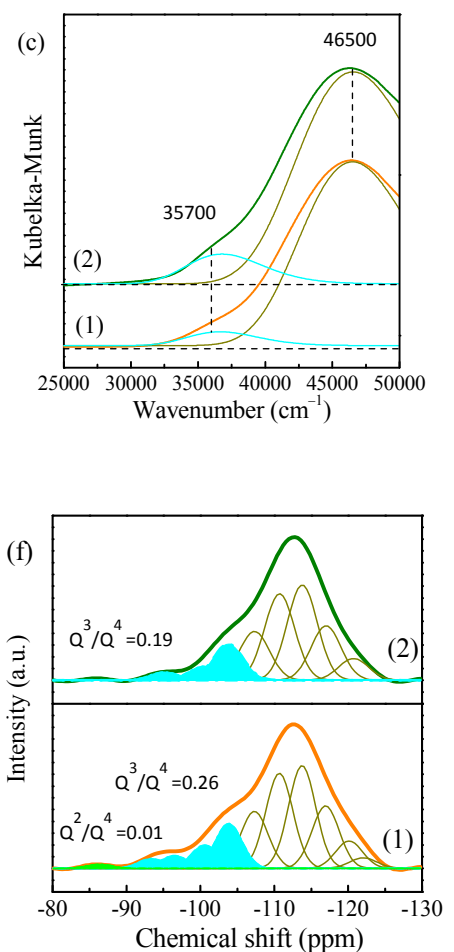

Fig. 11. XRD patterns (a), $\mathrm{N}_{2}$ adsorption-desorption isotherms at $77 \mathrm{~K}$ (b), UV-Vis spectra (c), ${ }^{19} \mathrm{~F}$ MAS NMR spectra (d), Ti $2 p$ XPS spectra (e) and ${ }^{29} \mathrm{Si}$ MAS NMR spectra (f) of Bf-Ti-MWW (1) and RF-Ti-MWW (2). 


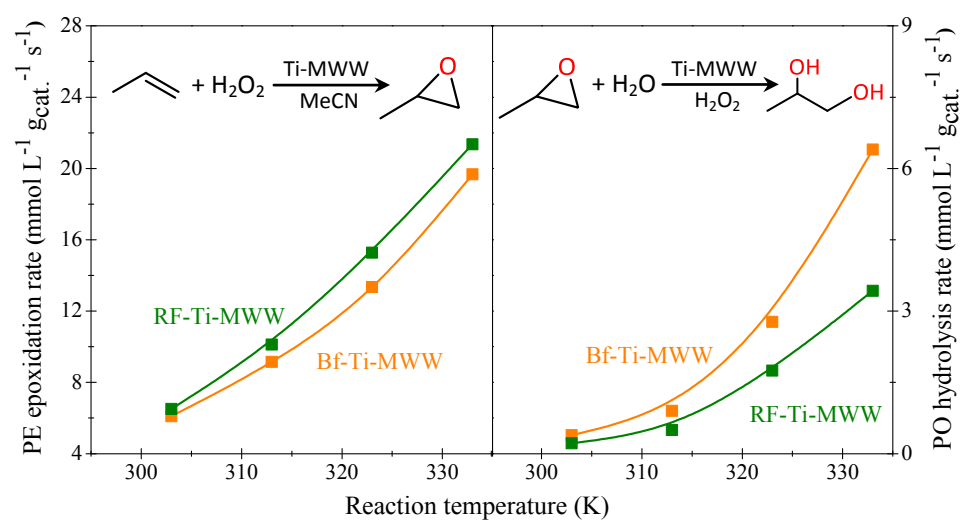

Fig. 12. Dependence of the reaction rate of propylene (PE) epoxidation (left) and PO hydrolysis (right) on reaction temperature over Bf-Ti-MWW and RF-Ti-MWW.

evaluated in a batch reactor. As listed in Table 1, the PO selectivity was still at high level of close to $100 \%$, while the $\mathrm{H}_{2} \mathrm{O}_{2}$ efficiency was improved to $93.9 \%$, above the usual $80 \%-90 \%$. However, the PO yield significantly increased from $48.4 \%$ for Bf-Ti-MWW to $61.1 \%$ for RF-Ti-MWW. In addition, through the PO hydrolysis experiments, it could be found that the PO conversion of RF-Ti-MWW was lower than that of Bf-Ti-MWW with $\mathrm{H}_{2} \mathrm{O}_{2}$ in the solvent of MeCN (Fig. S14), because the modification effectively quenched numerous Si-OH groups (Fig. S11). Moreover, the changes of the reaction rates of epoxidation and hydrolysis depending on the reaction temperature were investigated to reveal the behavior difference after modification. As shown in Fig. 12, it could be found that the epoxidation rates of both RF-Ti-MWW and Bf-Ti-MWW increased almost linearly with the increase of reaction temperature. Moreover, the epoxidation rate of RF-Ti-MWW was always higher than that of Bf-Ti-MWW. As for the PO hydrolysis rate, it increased rapidly and obviously with the increase of temperature for both of the two catalysts. However, the hydrolysis rate of RF-Ti-MWW was lower than that of Bf-Ti-MWW, especially at the higher reaction temperatures.

In a word, the binder-free Ti-MWW zeolite was chemically modified to improve the ratio of framework open $\mathrm{TiO}_{6}$ species and introduce the fluorine with electron-withdrawing inductive effect into Ti-zeolite frameworks to improve the LAS strength and the electropositivity of $\mathrm{Ti}$ sites. On one hand, the RF-Ti-MWW catalyst with stronger LAS had better ability to activate $\mathrm{H}_{2} \mathrm{O}_{2}$ to generate Ti-OOH and also enhanced the polarization of $\mathrm{O}^{\alpha-} \mathrm{O}^{\beta}$ in the active intermediates thus promoting the transfer of active $\mathrm{O}^{\alpha}[59]$. On the other hand, the $\mathrm{F}$ in Si-F groups could form stronger hydrogen bond with the end $\mathrm{H}$ in $\mathrm{Ti}-\mathrm{OOH}$, thus stabilizing active intermediates and promote the effective transfer of active $\mathrm{O}^{\alpha}$ [31]. The intermediate Ti-OOH could transfer the active $\mathrm{O}^{\alpha}$ to the double bond of propylene to form $\mathrm{PO}$, or react with $\mathrm{H}_{2} \mathrm{O}_{2}$ for ineffective oxidation decomposition, and these two pathways were competing with each other [23-25]. The promotion of the effective transfer of reactive $\mathrm{O}^{\alpha}$ would inhibit the reaction between the Ti-OOH and $\mathrm{H}_{2} \mathrm{O}_{2}$, thus improving the $\mathrm{H}_{2} \mathrm{O}_{2}$ efficiency. All these results illustrated that the epoxidation was accelerated effectively after modifica- tion, meanwhile the PO hydrolysis reactivity was decelerated, suggesting that the modification was effective in the HPPO process.

\subsubsection{The stability and reusability of RF-Ti-MWW}

To evaluate the catalytic performance of RF-Ti-MWW under continuous reaction mode, the reaction parameters were determined as WHSV $\mathrm{H}_{2} \mathrm{O}_{2}$ of $0.35 \mathrm{~h}^{-1}$, WHSV MeCN of $2.0 \mathrm{~h}^{-1}$, pressure of $2.0 \mathrm{MPa}, \mathrm{C}_{3}=/ \mathrm{H}_{2} \mathrm{O}_{2}$ molar ratio of 3 and co-feeding an appropriate concentration (15 $\left.\mathrm{mg} \mathrm{L}^{-1}\right)$ of alkaline additive $\left(\mathrm{NH}_{4}\right)_{2} \mathrm{CO}_{3}$. The initial reaction temperature was $313 \mathrm{~K}$, and as the reaction proceeded, the temperature was increased gradually to ensure the complete consumption of $\mathrm{H}_{2} \mathrm{O}_{2}$ (Fig. 13). When the temperature was raised to $333 \mathrm{~K}$, it remained unchanged until the catalyst was deactivated. The ratio of reaction temperature difference to the operating time was also used to determine the deactivation rate [60]. As shown in Fig. 13, the RF-Ti-MWW could run continuously and stably for as long as $2400 \mathrm{~h}$. The deactivation rate was as low as $8.23 \times 10^{-3} \mathrm{~K} \mathrm{~h}^{-1}$. Moreover, during this process, both of the $\mathrm{H}_{2} \mathrm{O}_{2}$ conversion and PO selectivity could be maintained above 99.5\%. Meanwhile,

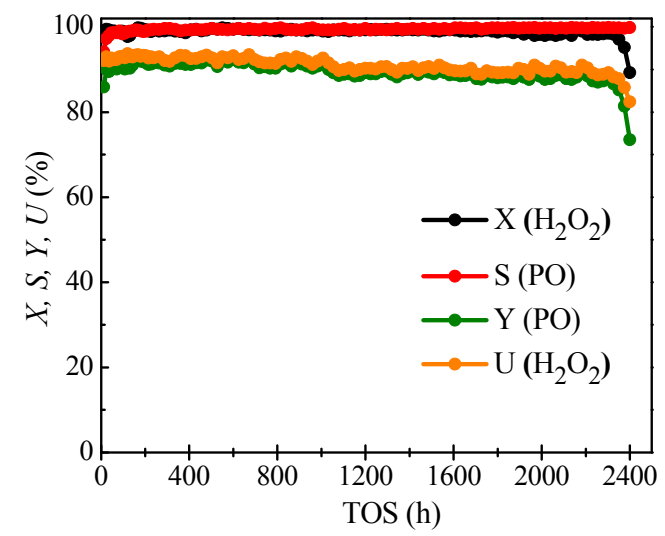

Fig. 13. The stability of RF-Ti-MWW catalyst for the continuous liquid-phase propylene epoxidation in a fixed-bed reactor. Reaction conditions: temperature 313-333 K; $\mathrm{C}_{3}=/ \mathrm{H}_{2} \mathrm{O}_{2}$ molar ratio, 3; pressure, 2 MPa; WHSV $\left(\mathrm{H}_{2} \mathrm{O}_{2}\right), 0.35 \mathrm{~h}^{-1}$ and WHSV (MeCN), $2 \mathrm{~h}^{-1} . X\left(\mathrm{H}_{2} \mathrm{O}_{2}\right), \mathrm{H}_{2} \mathrm{O}_{2}$ conversion; $S(\mathrm{PO})$, $\mathrm{PO}$ selectivity; $Y(\mathrm{PO})$, $\mathrm{PO}$ yield; $U\left(\mathrm{H}_{2} \mathrm{O}_{2}\right), \mathrm{H}_{2} \mathrm{O}_{2}$ utilization efficiency. 
the STY of PO could achieve as high as $543 \mathrm{~g} \mathrm{~kg}^{-1} \mathrm{~h}^{-1}$ and the mass of solvent $\mathrm{MeCN}$ required for $1.0 \mathrm{kmol}$ of $\mathrm{H}_{2} \mathrm{O}_{2}$ per feed was low as $194.3 \mathrm{~kg}$.

After the long-term experiment, the spent RF-Ti-MWW was collected and regenerated by calcination in air at $823 \mathrm{~K}$ for $6 \mathrm{~h}$. Compared with the fresh catalyst, the crystallinity, specific surface area and micropore volume of the spent catalyst decreased significantly, and they could be recovered completely after regeneration (Figs. S15 and S16, and Table S1). The TG curve of spent catalyst showed two stages of weight loss in the temperature range of 298-1000 K, in which the weight loss ascribed to the decomposition of organics in the high temperature region was about 14.2 wt\% (Fig. S17). And the TG curve of the regenerated catalyst turned to be almost the same as that of the fresh. The Ti content of RF-Ti-MWW was almost unchanged after the long-term run, but the residual framework boron species suffered serious leaching (Table S1). And no obvious difference in Ti coordination states could be found between the fresh and regenerated catalysts (Fig. S18), verifying the active Ti centers kept stable in HPPO process. In addition, all the resonances in the ${ }^{19} \mathrm{~F}$ MAS NMR spectrum were significantly weakened after regeneration (Fig. S19), implying the loss of F species during the long-term HPPO process. A batchwise propylene epoxidation was carried out to evaluate the catalytic performance of the three catalysts. As listed in Table S2, the spent catalyst was almost deactivation for the reaction, while the PO yield increased from $2.8 \%$ for the spent catalyst to $58.7 \%$ for the regenerated catalyst, slightly lower than $61.1 \%$ for the fresh catalyst. Therefore, it could be deduced that the deactivation of RF-Ti-MWW was mainly due to the deposition of organic byproducts within the micropores, which could be removed by calcination. Meanwhile, the framework Ti active sites and pore structure kept stable in such a long-term run. In addition, the loss of $\mathrm{SiO}_{3 / 2} \mathrm{~F}$ units resulted in lower activity of the regenerated catalyst compared to the fresh one. However, it was worth noting that the regenerated catalyst still showed the high catalytic activity (higher than Bf-Ti-MWW), and thus the loss of $\mathrm{F}$ species was not the main reason for the catalyst deactivation.

\section{Conclusions}

A binder-free formed Ti-MWW catalyst with attractive HPPO performance has been prepared via a combination method of shaping, recrystallization, and chemical modification of Ti sites. The dual-SDAs-assisted hydrothermal crystallization converted the amorphous silica binder in shaped extrudates to crystalline zeolite phase, enhancing the mechanic strength, improving the porosity to relieve the internal diffusion limitation, and constructing more active hexa-coordinated Ti species as well. The binder-free Ti-MWW catalyst exhibited extremely superior catalytic performance in propylene epoxidation. The recrystallization extended the lifetime of catalyst from about 75 to $640 \mathrm{~h}$ in the HPPO process. A further modification of the microenvironments of Ti active centers by successive PI and F treatment enhanced the epoxidation reactivity and prohibited the PO hydrolysis. Co-feeding an appropriate concentration of ammonium carbonate into the reactant mixture further increase the lifetime to $2400 \mathrm{~h}$ in single cycle with low solvent consumption. The deactivation of catalyst was mainly caused by the deposition of organic byproducts within the micropores, and the reactivity of the deactivated catalyst could be mostly recovered by calcination. The outstanding catalytic activity, stability and reusability implied the great potential of RF-Ti-MWW in industrial HPPO applications. This study also provided a novel strategy to construct highly active industrial Ti-zeolite catalysts.

\section{Conflicts of interest}

There are no conflicts to declare.

\section{Electronic supporting information}

Supporting information is available in the online version of this article.

\section{References}

[1] T. A. Nijhuis, M. Makkee, J. A. Moulijn, B. M. Weckhuysen, Ind. Eng. Chem. Res., 2006, 45, 3447-3459.

[2] M. J. Climent, A. Corma, S. Iborra, Chem. Rev., 2011, 111, 1072-1133.

[3] Y. Zuo, M. Liu, L. Hong, M. Wu, T. Zhang, M. Ma, C. Song, X. Guo, Ind. Eng. Chem. Res., 2015, 54, 1513-1519.

[4] V. H. Nguyen, B. S. Nguyen, H. T. Vo, C. C. Nguyen, S. R. Bae, S. Y. Kim, Q. V. Le, Catalysis, 2020, 10, 87-107.

[5] P. Bassler, H. G. Göbbel, M. Weidenbach, Chem. Eng. Trans., 2010, 21, 571-576.

[6] M. Lin, C. Xia, B. Zhu, H. Li, X. Shu, Chem. Eng. J., 2016, 295, 370-375.

[7] O. A. Kholdeeva, Catal. Sci. Technol., 2014, 4, 1869-1889.

[8] A. V. Sulimov, A. V. Ovcharova, A. A. Ovcharov, V. R. Flid, S. V. Leont'eva, L. G. Bruk, Z. Y. Pastukhova, M. R. Flid, Russ. Chem. Bull., 2016, 65, 2845-2849.

[9] F. Song, Y. Liu, L. Wang, H. Zhang, M. He, P. Wu, Stud. Surf. Sci. Catal., 2007, 170, 1236-1243.

[10] G. Li, X. Wang, H. Yan, Y. Liu, X. Liu, Appl. Catal. A, 2002, 236, 1-7.

[11] D. P. Serrano, R. Sanz, P. Pizarro, I. Moreno, P. de Frutos, S. Blázquez, Catal. Today, 2009, 143, 151-157.

[12] H. Xu, W. Tian, L. Xu, X. Jin, T. Xue, L. Chen, M. He, P. Wu., Chin. J. Catal., 2020, 41, 1109-1117.

[13] Z. Li, X. Jiang, G. Xiong, B. Nie, C. Liu, N. He, J. Liu, Catal. Sci. Technol., 2020, 10, 7829-7841.

[14] J. Zhou, J. Teng, L. Ren, Y. Wang, Z. Liu, W. Liu, W. Yang, Z. Xie, J. Catal., 2016, 340, 166-176.

[15] W. Song, Y. Zuo, G. Xiong, X. Zhang, F. Jin, L. Liu, X. Wang, Chem. Eng. J., 2014, 253, 464-471.

[16] X. Lu, H. Wu, J. Jiang, M. He, P. Wu, J. Catal, 2016, 342, 173-183.

[17] L. Xu, D. Huang, C. Li, X. Ji, S. Jin, Z. Feng, F. Xia, X. Li, F. Fan, C. Li, P. $\mathrm{Wu}$, Chem. Commun., 2015, 51, 9010-9013.

[18] F. Bonino, A. Damin, G. Ricchiardi, M. Ricci, G. Spanò, R. D'Aloisio, A. Zecchina, C. Lamberti, C. Prestipino, S. Bordiga, J. Phys. Chem. B, 2004, 108, 3573-3583.

[19] X. Nie, X. Ji, Y. Chen, X. Guo, C. Song, Mol. Catal, 2017, 441, 150-167.

[20] J. Limtrakul, C. Inntam, T. N. Truong, J. Mol. Catal. A, 2004, 207, 


\section{Graphical Abstract}

Chin. J. Catal., 2021, 42: 1561-1575 doi: 10.1016/S1872-2067(20)63759-7

Structured binder-free MWW-type titanosilicate with Si-rich shell for selective and durable propylene epoxidation

Jinpeng Yin, Xin Jin, Hao Xu *, Yejun Guan, Rusi Peng, Li Chen, Jingang Jiang, Peng Wu*

East China Normal University

A binder-free Ti-MWW catalyst with attractive HPPO performance has been prepared via a combination method of shaping, recrystallization, and chemical modification of Ti sites.

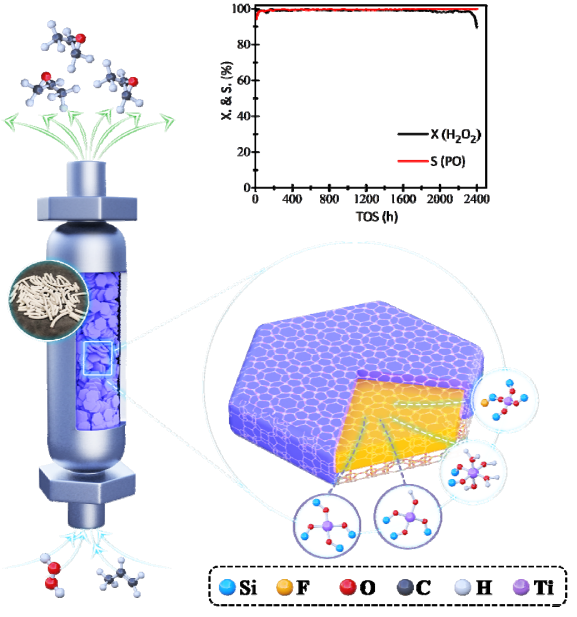

105, 2897-2905

[40] D. T. Bregante, D. W. Flaherty, ACS Catal., 2019, 9, 10951-10962.

[41] M. Trzpit, M. Soulard, J. Patarin, N. Desbiens, F. Cailliez, A. Boutin, I. Demachy, A. H. Fuchs, Langmuir, 2007, 23, 10131-10139.

[42] A. Özgür Yazaydın, R. W. Thompson, Microporous Mesoporous Mater., 2009, 123, 169-176.

[43] K. Zhang, R. P. Lively, J. D. Noel, M. E. Dose, B. A. McCool, R. R. Chance, W. J. Koros, Langmuir, 2012, 28, 8664-8673.

[44] X. Fang, Q. Wang, A. Zheng, Y. Liu, L. Lin, H. Wu, F. Deng, M. He, P. Wu, Phys. Chem. Chem. Phys., 2013, 15, 4930-4938.

[45] C. Lamberti, S. Bordiga, D. Arduino, A. Zecchina, F. Geobaldo, G. Spanó, F. Genoni, G. Petrini, A. Carati, F. Villain, G. Vlaic, J. Phys. Chem. B, 1998, 102, 6382-6390.

[46] X. Wang, X. Zhang, Y. Wang, H. Liu, J. Wang, J. Qiu, H. L. Ho, W. Han, K. L. Yeung, Chem. Eng. J., 2011, 175, 408-416.

[47] J. Yin, H. Xu, B. Wang, W. Tian, J. Yin, J. Jiang, P. Wu, Catal. Sci. Technol., 2020, 10, 6050-6064.

[48] G. Tozzola, M.A. Mantegazza, G. Ranghino, G. Petrini, S. Bordiga, G. Ricchiardi, C. Lamberti, R. Zulian, A. Zecchina, J. Catal., 1998, 179, 64-71.

[49] S. Bordiga, A. Damin, G. Berlier, F. Bonino, G. Ricchiardi, A. Zecchina, C. Lamberti, Int. J. Mol. Sci., 2001, 2, 167-182.

[50] C. Li, G. Xiong, J. Liu, P. Ying, Q. Xin, Z. Feng, J. Phys. Chem. B, 2001, 105, 2993-2997.

[51] P. Wu, T. Komatsu, T. Yashima, J. Phys. Chem. B, 1996, 100, 10316-10322.

[52] Y. Kuwahara, K. Nishizawa, T. Nakajima, T. Kamegawa, K. Mori, H. Yamashita, J. Am. Chem. Soc., 2011, 133, 12462-12465.

[53] Y. Luo, Y. Zhu, J. Pan, X. Chen, Green Chem., 2020, 22, 1681-1697.

[54] D. T. Bregante, P. Priyadarshini, D. W. Flaherty, J. Catal., 2017, 348, 75-89.

[55] Y. Wang, Y. Liu, X. Li, H. Wu, M. He, P. Wu, J. Catal., 2009, 266, 258-267.

[56] K. Sadowska, K. Góra-Marek, J. Datka, J. Phys. Chem. C, 2013, 117, 9237-9244.

[57] D. T. Bregante, N. E. Thornburg, J. M. Notestein, D. W. Flaherty, ACS Catal., 2018, 8, 2995-3010.

[39] P. Wu, T. Tatsumi, T. Komatsu, T. Yashima, J Phys. Chem. B, 2001, 
[58] L. Wang, Y. Liu, W. Xie, H. Zhang, H. Wu, Y. Jiang, M. He, P. Wu, J. Catal., 2007, 246, 205-214.

[59] R. R. Sever, T. W. Root, J. Phys. Chem. B, 2003, 107, 4080-4089.
[60] D. Riedel, J. H. Teles, U. Wegerle, A. N. Parvulescu, A. Schroeder, L. Spiske, D. Urbanczyk, U. Mueller, W. Witzl, M. Weidenbach, CN201480052455A, 2014.

\title{
富硅壳层结构的无粘结剂MWW钛硅分子篮用作高选择性、 高稳定性的丙烯环氧化
}

\author{
尹金鹏，金 金金，徐 浩\#，关业军，彭如斯，陈 丽，蒋金刚，吴 鹏" \\ 华东师范大学化学与分子工程学院, 绿色化学与化工过程上海市重点实验室, 上海200062
}

\begin{abstract}
摘要: 环氧丙烷(PO)是一种重要的高活性丙烯衍生物, 被广泛用于生产各种商业化学品(丙二醇、聚氨酯和表面活性剂等). 目前, 工业生产 $\mathrm{PO}$ 主要有传统的氯醇法(CP), 共氧化法(叔丁基过氧化氢法、乙苯过氧化氢法和异丙苯过氧化氢法)和过氧 化氢直接氧化法(HPPO). 其中, HPPO具有反应条件温和、活性高、选择性好和污染小等特点, 被认为是一种极具竞争力的 环境友好型 $\mathrm{PO}$ 生产工艺. 目前, 基于 $\mathrm{TS}-1 / \mathrm{H}_{2} \mathrm{O}_{2}$ /甲醇催化体系的固定床连续HPPO工艺已经实现了工业化(陶氏/巴斯夫、赢 创/伍德和中国石化). 但是, 溶剂甲醇会导致 $\mathrm{PO}$ 醇解开环, 使 $\mathrm{PO}$ 选择性降低, 而且甲醇和 $\mathrm{PO}$ 存在共沸问题, 使 $\mathrm{PO}$ 纯化分离 的操作复杂, 能耗和成本增加. 本课题组之前报道过Ti-MWW在溶剂乙腈中比TS-1在溶剂甲醇中表现出更好的催化性能 (Stud. Surf. Sci. Catal., 2007, 170, 1236-1243.), 尤其是质子型惰性溶剂乙腈的存在可以消除PO醇解副反应, 极大地提高了 PO选择性. 因此, 开发和设计以乙腈为溶剂的工业Ti-MWW催化剂具有重要的学术和应用价值. 工业HPPO过程通常在固 定床反应器中进行, 需要具有一定机械强度的催化剂来降低压降, 因此需要对催化剂原粉进行成型处理. 粘结剂是制备成 型催化剂的必要添加剂, 通常是催化惰性组分, 但是它们的引入会降低催化剂中有效活性组分的比例, 而且大量的粘结剂 会覆盖在沸石的表面及孔口, 导致活性中心的可接近性和利用率降低. 因此, 设计高性能的工业Ti-MWW催化剂既要消除 粘结剂对底物向活性位点扩散的负面影响, 又要保持较高的机械强度.

本文首次提出了一种可控的二次晶化策略,在双有机结构导向剂 $N, N, N$-三甲基-1-金刚烷基氢氧化铵和六亚甲基亚胺 的作用下, 成功地将成型 $\mathrm{SiO}_{2} / \mathrm{Ti}-\mathrm{MWW}$ 催化剂中的粘结剂组分转化为 $\mathrm{MWW}$ 沸石相, 形成了具有富硅壳层的整体式无粘结 剂Ti-MWW催化剂, 提高了扩散效率的同时也保证了机械强度. 在二次晶化过程中, 母体Ti-MWW发生了部分溶硅, 形成 了大量的内部硅羟基巢, 同时部分骨架 $\mathrm{TiO}_{4}$ 物种转变为了具有更强路易斯酸性(LAS)的开放状态的 $\mathrm{TiO}_{6}$ 物种, 提高了催化 剂对于 $\mathrm{H}_{2} \mathrm{O}_{2}$ 的富集和活化能力, 使得PO收率从 $13.1 \%$ 提高到 $48.4 \%$, 催化使用寿命从 $75 \mathrm{~h}$ 延长到了 $640 \mathrm{~h}$. 为了进一步提高 催化性能, 我们对催化剂进行了哌啶和氟化处理, 提高了催化剂中 $\mathrm{TiO}_{6}$ 物种的比例; 将有强拉电子效应的氟引入分子篮骨 架, 提高了 Ti的LAS强度. 一方面, 具有强LAS的改性催化剂能够促进 $\mathrm{H}_{2} \mathrm{O}_{2}$ 的活化形成Ti-OOH中间体, 提高Ti-OOH中 $\mathrm{O}^{\alpha}-\mathrm{O}^{\beta}$

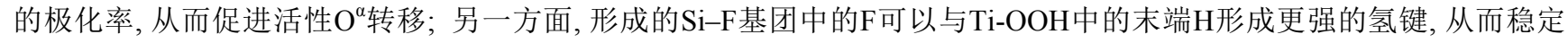
$\mathrm{Ti}-\mathrm{OOH}$, 促进活性 $\mathrm{O}^{\alpha}$ 有效转移和环氧化过程, 抑制了 $\mathrm{H}_{2} \mathrm{O}_{2}$ 的无效分解. 此外, 大量内部硅羟基巢被淬灭, 抑制了 $\mathrm{PO}$ 水解副 反应的发生. 改性后的无粘结剂Ti-MWW催化剂具有 $2400 \mathrm{~h}$ 的超长寿命, PO时空收率达到了 $543 \mathrm{~g} \mathrm{~kg}^{-1} \mathrm{~h}^{-1}$, 每 $1 \mathrm{kmol}_{2} \mathrm{O}_{2}$ 消耗的溶剂乙腈质量仅为 $194.3 \mathrm{~kg}$.
\end{abstract}

关键词: 丙烯环氧化; 钛硅分子篮; 无粘结剂成型催化剂; 二次晶化; 微环境

收稿日期: 2020-12-11. 接受日期: 2021-01-11. 上网时间: 2021-05-05.

*通讯联系人. 电话/传真: (021)62232292; 电子信箱: pwu@chem.ecnu.edu.cn

\#通讯联系人. 电子信箱: hxu@chem.ecnu.edu.cn

基金来源：国家自然科学基金(21533002，21872052，21972044); 国家重点研发计划(2016YFA0202804); 中央高校基本科研业务费 专项资金.

本文的电子版全文由Elsevier出版社在ScienceDirect上出版(http://www.sciencedirect.com/journal/chinese-journal-of-catalysis). 